\title{
Ab Initio Conformational Study of Two Lewis X Analogues
}

\author{
Gábor I. Csonka* \\ Department of Inorganic Chemistry, Budapest University of Technology and Economics, \\ H-1521 Budapest, Hungary
}

\author{
Carlos P. Sosa \\ Cray Research/Silicon Graphics Inc., 655 F Lone Oak Dr., Eagan, Minnesota 55123
}

Received: February 18, 2000; In Final Form: April 25, 2000

\begin{abstract}
This paper presents the first ab initio conformational study for analogues of a histo-blood group carbohydrate antigen, Le $^{\mathrm{x}}$ (Gal- $\beta-1,4-[$ Fuc- $\alpha-1,3]-$ GlcNAc). In these analogues, the GlcNAc group of Le ${ }^{\mathrm{x}}$ was replaced by a cyclohexanediol or an ethanediol group. The lowest energy conformers of these molecules were first found by the MM2*-SUMM conformational search technique. The molecular geometries and energies of lowest energy rotamers (within a $3 \mathrm{kcal} / \mathrm{mol}$ energy window) were further analyzed at the HF/6-31G(d) level of theory. This study provides a detailed description of the hydrogen-bonding properties of the low-energy conformers yielded by the MM2* and ab initio methods. The key torsion angles for Fuc- $\alpha-1,3-$ GlcNAc and Gal- $\beta-1,4-G l c N A c$ glycosidic bonds in Le ${ }^{\mathrm{x}}$ mostly keep their value in the different environments (solid, liquid, and gas phase). The ab initio torsion angles agree considerably better with the experimental results than the MM2* results. Another essential difference between the MM2* and ab initio results is that the latter provide better differentiation of the rotamers. Complexes with selectins introduced varying levels of distortion of $\mathrm{Le}^{\mathrm{x}}$, with the most tightly bound structure being most distorted. Nonstacked rotamers occur only once among the rotamers of 1,2-cyclohexanediol analogue, and that rotamer is not particularly stable $(\Delta E=2.3 \mathrm{kcal} /$ mol). However, such kind of rotamers are more frequent among the rotamers of 1,2-ethanediol analogue. This clearly shows that while the conformational space of 1,2-cyclohexanediol analogue is rather similar to that of $\mathrm{Le}^{\mathrm{x}}$, the conformational space of 1,2-ethanediol analogue is considerably less similar.
\end{abstract}

\section{Introduction}

The search for analogues of sialyl $\mathrm{Le}^{\mathrm{x}}\left(\mathrm{sLe}^{\mathrm{x}}, \mathrm{NeuAc}-\alpha-2,3-\right.$ Gal- $\beta$-1,4-[Fuc- $\alpha-1,3]$-GlcNAc, a blood group carbohydrate antigen tetrasaccharide), has two goals: simplification of the structure to small and stable molecules, and preservation of the biological activity. The conformation ${ }^{1,2}$ and the key structural features ${ }^{3}$ of $\mathrm{sLe}^{\mathrm{x}}$, required for recognition, were reviewed recently. ${ }^{4}$ The 2-, 3-, and 4-hydroxyl groups of $\alpha$-L-fucose, the 4-, and 6-hydroxyl groups of D-galactose, and the carboxylate group of sialic acid play essential roles in the E-, P-, and L-selectin recognition of $\mathrm{sLe}^{\mathrm{x}} .^{5}$ It has been found that a $\mathrm{CH}_{2} \mathrm{COO}^{-}$group on the 3-position of galactose sufficiently mimics NeuAc. ${ }^{4}$ The next step was to replace GlcNAc. While this group contains none of the groups critical to binding, it was thought to be important for preorganizing the $\mathrm{SLe}^{\mathrm{x}}{ }^{4}$ Experimental results show that a 1,2-cyclohexanediol group sufficiently mimics the shape and rigidity of the replaced pyranose ring. Surprisingly, 1,2-ethanediol is almost equally effective as a replacement of GlcNAc. ${ }^{6}$ However, in derivatives in which Gal has also been removed, the difference between the two replacements becomes more pronounced. ${ }^{4}$ Otherwise, the link chosen to replace the GlcNAc rarely improves the binding constant and it is believed that the 1,2-cyclohexanediol is an energetically neutral substitution. ${ }^{4}$

In our previous study, we analyzed the MM2* and HF/6$31 \mathrm{G}(\mathrm{d})$ conformational space of the desialylated trisaccharide Le $^{\mathrm{x}}$ (Gal- $\beta$-1,4-[Fuc- $\left.\alpha-1,3\right]-$ GlcNAc- $\beta$ ). ${ }^{7}$ (This molecule is a stage-specific embryonic marker in cell-cell interactions and a signaling molecule for some host-pathogen recognition.) $\mathrm{Le}^{\mathrm{x}}$ has a relatively rigid structure according to $\mathrm{NMR},{ }^{2,5,8}$ and $\mathrm{X}-\mathrm{ray}^{9}$ experiment. This rigid structure was confirmed by MM2* and HF/6-31G(d) results. ${ }^{7}$ A detailed description of the intramolecular hydrogen-bonding network was also provided in ref 7. Carbohydrates are rather difficult tests for MM methods because they have densely packed highly polar functional groups, and the conformational energies depend on stereoelectronic effects. In this respect our earlier results show that for example the MM2* method provide good qualitative results for the lowest energy rotamers of monosaccharides. However, it provides an energetically compressed conformational space with incorrectly ordered rotamers in the higher energy region. ${ }^{10-13}$ Earlier studies have found that the HF/6-31G(d) and cc-pVDZ results provide quite good relative energies for monosaccharides that are close to the results of the most expensive calculations. ${ }^{14}$ This is discussed in our previous paper on $\mathrm{Le}^{\mathrm{x}}{ }^{7}$ Barrows et al. ${ }^{14}$ summarized the performance of the best MM methods for energies of D-glucose rotamers and they have found that $\mathrm{HF}$ / 6-31G(d) method is clearly superior compared to any MM parametrization. Much effort has been made recently to parametrize molecular mechanics (MM) methods for saccharides in the gas phase using HF/6-31G(d) results..$^{15-18}$

The earlier results showed that the HF/6-31G(d) equilibrium molecular geometries might differ noticeably from equilibrium molecular geometries calculated at correlated (mostly MP2 or GGA-DFT) levels of theory. ${ }^{11,14}$ However, these geometry variations result in small changes in the relative energies. For example, when the optimized HF/6-31G(d) geometries of 

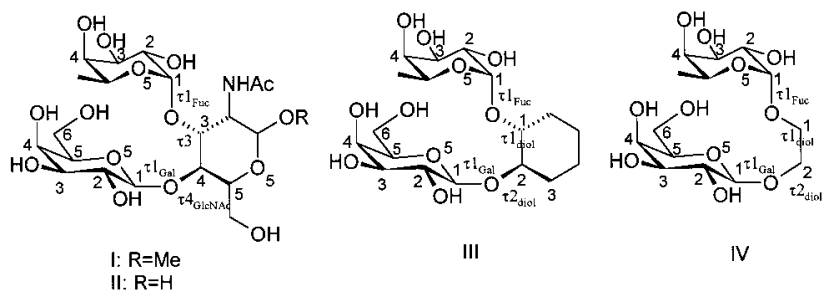

Figure 1. Schematic representation and the numbering of the atoms of the molecules studied in the present paper. The numbers of the atoms are based on standard carbohydrate nomenclature for glucose rings. For I and II, $\tau 1_{\mathrm{Fuc}}=\tau\left(\mathrm{C} 2_{\mathrm{Fuc}}-\mathrm{C} 1_{\mathrm{Fuc}}-\mathrm{O}[1,3]_{\mathrm{link}}-\mathrm{C} 3_{\mathrm{GlcNAc}}\right), \tau 3_{\mathrm{GlcNAc}}=$ $\tau\left(\mathrm{C}_{\mathrm{Fuc}}-\mathrm{O}[1,3]_{\text {link }}-\mathrm{C} 3_{\mathrm{GlcNAc}}-\mathrm{C} 4_{\mathrm{GlcNAc}}\right), \tau 4_{\mathrm{GlNNAc}}=\tau\left(\mathrm{C} 1_{\mathrm{Gal}}-\mathrm{O}[1,4]_{\text {link }}-\right.$ $\left.\mathrm{C} 4_{\mathrm{GlcNAc}}-\mathrm{C} 5_{\mathrm{GlcNAc}}\right), \tau 1_{\mathrm{Gal}}=\tau\left(\mathrm{C} 2_{\mathrm{Gal}}-\mathrm{C} 1_{\mathrm{Gal}}-\mathrm{O}[1,4]_{\text {link }}-\mathrm{C} 4_{\mathrm{GlcNAc}}\right)$. For III and IV, $\tau 1_{\text {Fuc }}=\tau\left(\mathrm{C} 2_{\text {Fuc }}-\mathrm{C} 1_{\text {Fuc }}-\mathrm{O}[1,1]_{\text {link }}-\mathrm{C} 1_{\text {diol }}\right)$, and $\tau 1_{\text {diol }}=$ $\tau\left(\mathrm{C}_{\text {Fuc }}-\mathrm{O}[1,3]_{\text {link }}-\mathrm{C} 1_{\text {diol }}-\mathrm{C} 2_{\text {diol }}\right)$. For III, $\tau 2_{\text {diol }}=\tau\left(\mathrm{C}_{\text {Gal }}-\mathrm{O}[1,2]_{\text {link }}-\right.$ $\left.\mathrm{C} 2_{\text {diol }}-\mathrm{C} 3_{\text {diol }}\right)$, and for $\mathbf{I V}, \tau 2_{\text {diol }}=\tau\left(\mathbf{C} 1_{\text {Gal }}-\mathrm{O}[1,2]_{\text {link }}-\mathrm{C} 2_{\text {diol }}-\mathrm{C} 1_{\text {diol }}\right)$ $-240^{\circ} . \tau 1_{\mathrm{Gal}}=\tau\left(\mathrm{C} 2_{\mathrm{Gal}}-\mathrm{C} 1_{\mathrm{Gal}}-\mathrm{O}[1,2]_{\text {link }}-\mathrm{C} 2_{\text {diol }}\right)$.

D-glucose rotamers are subsequently reoptimized using various correlation methods and basis sets, those initial and final energies differ by only $0.0-0.2 \mathrm{kcal} / \mathrm{mol}$. However, different methods and basis sets result in variations of $5-10 \mathrm{kcal} / \mathrm{mol}$ or more in the relative energies of different members of the set of conformers with or without geometry reoptimization. ${ }^{11,14}$

In the present study, we compare the conformational space of the four molecules shown in Figure 1. The conformational space of III (1,2-cyclohexanediol derivative) is considerably simpler than that of the $\mathrm{Le}^{\mathrm{x}}$ (531 441 rotamers vs 28697814 possible rotamers). First, we use the MM2*-SUMM method for the exploration of the conformational space of torsion angles (cf. Figure 2). Then we reoptimize the geometries of the lowest energy structures obtained by the MM $2 *$-SUMM method by HF/6-31G(d) method. Finally, we compare the calculations with available experimental evidence.

\section{Computational Methodology}

2.1. Conformational Searching. The search for stable conformers in the conformational space of the selected molecules (cf. Figure 2) was carried out with the particularly efficient systematic unbounded multiple minimum search technique $^{19}$ (SUMM) available in the MacroModel 5.0 program package. ${ }^{20}$ Energies were calculated with the MM2* force field in MacroModel, which is a slight variant of authentic MM2. ${ }^{21}$ The most important difference is in the electrostatic equation. A recent comparison of a series of molecular mechanics methods has shown that the accuracy in relative conformational energies is apparently equal for MM2*, MM2(91), and MM3(92). ${ }^{22}$

During the conformational searches the puckering of the pyranose rings were not changed. The most stable ${ }^{4} \mathrm{C}_{1}$ pyranose ring form for the $\mathrm{D}$-mannose and ${ }^{1} \mathrm{C}_{4}$ ring form for the $\mathrm{L}$-fucose were used in this study. The search was limited to the various rotamers of the freely rotatable bonds. The 4000 structures generated by SUMM procedure were minimized to yield unique conformers within an energy window of $5.0 \mathrm{kcal} / \mathrm{mol}$ above the global minimum. Then, a new conformational search was started from the global minimum and limited to 2000 structures. The two resulting conformational spaces were compared. It was found that the first SUMM search was sufficient for III and IV, and no new low-energy rotamers were found in the subsequent search. Geometry optimizations were carried out with a truncated Newton conjugate gradient (TCNG) technique, with the maximum number of iterations set to 200 and using a convergence criterion of 0.01 for the gradient norm. For III, this procedure resulted in $1,4,15$, and 56 rotamers within 1.0, $2.0,3.0$, and $5.0 \mathrm{kcal} / \mathrm{mol}$ of the global minimum, respectively.
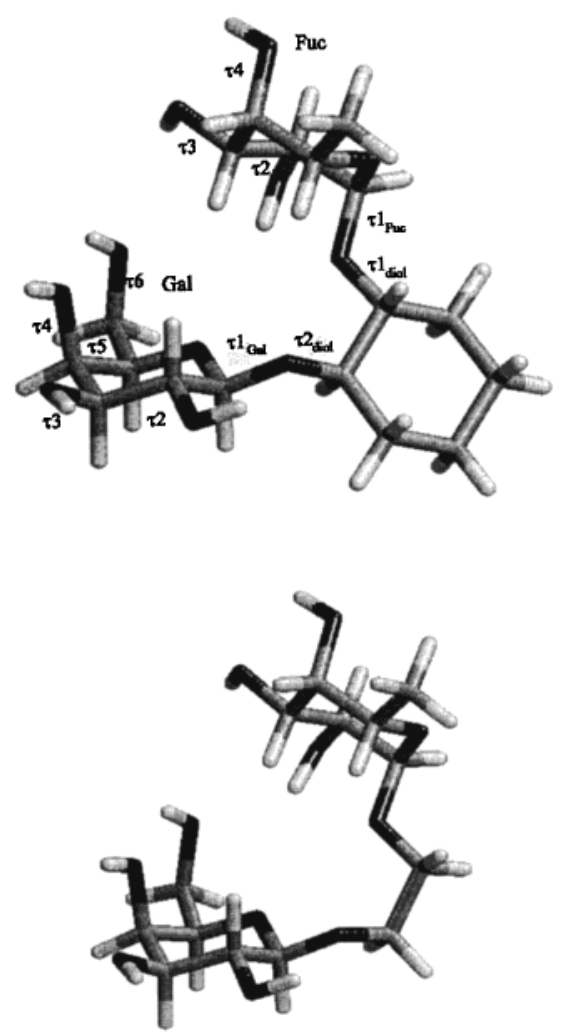

Figure 2. 3D structures of the most stable MM2* conformations for III (upper) and IV (lower). The numbers of the atoms are based on standard carbohydrate nomenclature for glucose rings (cf. Figure 1). The numbers of the torsion angles is shown in the upper structure. $\tau \mathrm{n}=\tau(\mathrm{C}(n+1)-\mathrm{C} n-\mathrm{O}-\mathrm{R})$, where $\mathrm{R}=\mathrm{C}$ or $\mathrm{H}$ and $n=1,2,3,4$. The $\tau 5$ torsion angle is defined as $\mathrm{O}-\mathrm{C} 5-\mathrm{C} 6-\mathrm{O}$, the $\tau 6$ torsion angle is defined as $\mathrm{C} 5-\mathrm{C} 6-\mathrm{O}-\mathrm{H}$ in Gal. $\tau 1_{\mathrm{Fuc}}=\tau\left(\mathrm{C} 2_{\mathrm{Fuc}}-\mathrm{C} 1_{\mathrm{Fuc}}-\mathrm{O}[1,1]_{\text {link }}-\right.$ $\left.\mathrm{C} 1_{\text {diol }}\right), \tau 1_{\text {diol }}=\tau\left(\mathrm{C}_{\text {Fuc }}-\mathrm{O}[1,3]_{\text {link }}-\mathrm{C}_{\text {diol }}-\mathrm{C} 2_{\text {diol }}\right), \tau 2_{\text {diol }}=\tau\left(\mathrm{C}_{\text {Gal }}-\right.$ $\left.\mathrm{O}[1,2]_{\text {link }}-\mathrm{C} 2_{\text {diol }}-\mathrm{C} 3_{\text {diol }}\right)$, and $\tau 1_{\text {Gal }}=\tau\left(\mathrm{C} 2_{\text {Gal }}-\mathrm{C} 1_{\text {Gal }}-\mathrm{O}[1,2]_{\text {link }}-\mathrm{C} 2_{\text {diol }}\right)$.

For $\mathbf{I V}$, this procedure resulted in $1,6,14$, and 23 rotamers within $1.0,2.0,3.0$, and $5.0 \mathrm{kcal} / \mathrm{mol}$ of the global minimum, respectively. The global minimum was found more than 22 times in both searches.

2.2. Ab Initio Methods. The minima obtained by the MM2*SUMM searches were fully optimized at the HF/6-31G(d) level of theory. All the optimizations were performed in redundant internal coordinates using the Berny algorithm ${ }^{23}$ built into the Gaussian $98^{24}$ programs. All the time-consuming optimizations were carried out on a CRAY C90. Many of the calculations were carried out using 2 and 4 CPUs.

\section{Results and Discussion}

3.1. Molecular Geometries. 3.1.1. Experimental Glycosidic Torsion Angles in $\mathbf{L e}^{\mathbf{x}}$. The glycosidic torsion angles play an essential role in the conformational shape of the $\mathrm{Le}^{\mathrm{x}}$ analogues; thus, we analyze these torsion angles first. Since the oxygen atom in glycosidic bonds connects two carbon atoms, this oxygen can be identified as part of the glycosidic bond by two numbers, each number corresponding to the adjacent carbon atoms (e.g., for an oxygen in a 1,3 glycosidic bond we use the notation $\mathrm{O}[1,3])$. In order to compare our theoretical results with experiment, we recall the notation reported by Poppe et al. ${ }^{5}$ On the basis of their NMR NOE experiments they define several $\mathrm{H}-\mathrm{C}-\mathrm{O}-\mathrm{C}$ torsions as follows: for the Fuc- $\alpha-1,3-\mathrm{GlcNAc}$ glycosidic bond, $\Phi 3=\tau\left(\mathrm{H}_{\mathrm{Fuc}}-\mathrm{C} 1_{\mathrm{Fuc}}-\mathrm{O}[1,3]_{\text {link }}-\mathrm{C} 3_{\mathrm{GlcNAc}}\right)$, $\Psi 3=\tau\left(\mathrm{C}_{\text {Fuc }}-\mathrm{O}[1,3]_{\text {link }}-\mathrm{C} 3_{\mathrm{GlcNAc}}-\mathrm{H} 3_{\mathrm{GlcNAc}}\right)$; and for the Gal$\beta$-1,4-GlcNAc glycosidic bond, $\Phi 4=\tau\left(\mathrm{H}_{\mathrm{Gal}}-\mathrm{Cl}_{\mathrm{Gal}}-\mathrm{O}[1,4]_{\text {link }}-\right.$ 
TABLE 1: Experimental $\tau \mathbf{1}_{\mathrm{Fuc}}, \tau \mathbf{3}_{\mathrm{GlcNAc}}, \tau \mathbf{4}_{\mathrm{GlcNAc}}$, and $\tau \mathbf{1}_{\mathrm{Gal}}$ Torsion Angles in Le $^{\mathrm{x}}$ and SLe ${ }^{\mathrm{x}}$

\begin{tabular}{|c|c|c|c|c|}
\hline & $\tau 1_{\text {Fuc }}$ & $\tau 3_{\mathrm{GlcNAc}}$ & $\tau 4_{\mathrm{GlcNAc}}$ & $\tau 1_{\mathrm{Gal}}$ \\
\hline $\mathrm{X}$-ray $1^{a}$ & 161.3 & 139.0 & -107.7 & 169.6 \\
\hline X-ray $2^{a}$ & 166.7 & 138.7 & -104.6 & 160.0 \\
\hline solution $^{b}$ & $168 \pm 2$ & $142 \pm 1$ & $-103 \pm 2$ & $167 \pm 2$ \\
\hline bound $\mathrm{E}^{b}$ & $190 \pm 3$ & $133 \pm 2$ & $-88 \pm 3$ & $146 \pm 5$ \\
\hline bound $\mathrm{P}^{b}$ & $180 \pm 10$ & $144 \pm 6$ & $-103 \pm 4$ & $166 \pm 4$ \\
\hline bound $\mathrm{L}^{b}$ & $162 \pm 11$ & $135 \pm 3$ & $-96 \pm 12$ & $154 \pm 11$ \\
\hline
\end{tabular}

${ }^{a}$ Calculated from the $\mathrm{Le}^{\mathrm{x}}$ structure published in ref 9. $\tau 1_{\text {Fuc }}=$ $\tau\left(\mathrm{C} 2_{\mathrm{Fuc}}-\mathrm{C} 1_{\mathrm{Fuc}}-\mathrm{O}[1,3]_{\text {link }}-\mathrm{C} 3_{\mathrm{GlcNAc}}\right), \tau 3_{\mathrm{GlcNAc}}=\tau\left(\mathrm{C} 1_{\mathrm{Fuc}}-\mathrm{O}[1,3]_{\text {link }}-\right.$ $\left.\mathrm{C} 3_{\mathrm{GlcNAc}}-\mathrm{C} 4_{\mathrm{GlcNAc}}\right), \tau 4_{\mathrm{GlcNAc}}=\tau\left(\mathrm{Cl}_{\mathrm{Gal}}-\mathrm{O}[1,4]_{\text {link }}-\mathrm{C} 4_{\mathrm{GlcNAc}}-\mathrm{C} 5_{\mathrm{GlcNAc}}\right)$, and $\tau 1_{\mathrm{Gal}}=\tau\left(\mathrm{C} 2_{\mathrm{Gal}}-\mathrm{C} 1_{\mathrm{Gal}}-\mathrm{O}[1,4]_{\text {link }}-\mathrm{C}_{\mathrm{GlcNAc}}\right)$. For atom numbers see Figure $1 .{ }^{b}$ The published NOE NMR C $-\mathrm{O}-\mathrm{C}-\mathrm{H}$ torsion angles ${ }^{5}$ for $\mathrm{sLe}^{\mathrm{x}}$ were transformed to $\mathrm{C}-\mathrm{O}-\mathrm{C}-\mathrm{C}$ torsion angles using a function of $\mathrm{C}-\mathrm{O}-\mathrm{C}-\mathrm{C}$ vs $\mathrm{C}-\mathrm{O}-\mathrm{C}-\mathrm{H}$ derived from ab initio results (see text for details). To facilitate the overview, the torsion angles differing more than $\pm 6^{\circ}$ form the NOE NMR value in the solution are set in bold.

$\left.\mathrm{C} 4_{\mathrm{GlcNAc}}\right), \Psi 4=\tau\left(\mathrm{C} 1_{\mathrm{Gal}}-\mathrm{O}[1,4]_{\text {link }}-\mathrm{C} 4_{\mathrm{GlcNAc}}-\mathrm{H} 4_{\mathrm{GlcNAc}}\right)$. The approximate $\mathrm{C}-\mathrm{C}-\mathrm{O}-\mathrm{C}$ torsion angles used in the present study can be obtained from $\mathrm{H}-\mathrm{C}-\mathrm{O}-\mathrm{C}$ angles of Poppe et al. in the following way:

$\tau 1_{\mathrm{Fuc}}=\tau\left(\mathrm{C} 2_{\mathrm{Fuc}}-\mathrm{C} 1_{\mathrm{Fuc}}-\mathrm{O}[1,3]_{\text {link }}-\mathrm{C} 3_{\mathrm{GlcNAc}}\right)=$ $0.99 \Phi 3+120^{\circ}$

$\tau 3_{\mathrm{GlcNAc}}=\tau\left(\mathrm{C}_{\mathrm{Fuc}}-\mathrm{O}[1,3]_{\text {link }}-\mathrm{C} 3_{\mathrm{GlcNAc}}-\mathrm{C} 4_{\mathrm{GlcNAc}}\right)=$ $0.93 \Psi 3+120^{\circ}$

$\tau 4_{\mathrm{GlcNAc}}=\tau\left(\mathrm{C}_{\mathrm{Gal}}-\mathrm{O}[1,4]_{\text {link }}-\mathrm{C} 4_{\mathrm{GlcNAc}}-\mathrm{C} 5_{\mathrm{GlcNAc}}\right)=$ $0.90 \Psi 4-119^{\circ}$

$\tau 1_{\mathrm{Gal}}=\tau\left(\mathrm{C} 2_{\mathrm{Gal}}-\mathrm{C} 1_{\mathrm{Gal}}-\mathrm{O}[1,4]_{\text {link }}-\mathrm{C} 4_{\mathrm{GlcNAc}}\right)=$

$0.95 \Phi 4+123^{\circ}$

These equations were calculated from our ab initio structures for $\mathrm{Le}^{\mathrm{x}} .^{7}$ Their constants are valid only for the small $\left(<30^{\circ}\right)$ ranges given in Table 1 . These transformations allow us to use only the heavy atom $\mathrm{C}-\mathrm{C}-\mathrm{O}-\mathrm{C}$ torsion angles to compare the solid-, liquid-, and gas-phase structures, avoiding the uncertainties arising from $\mathrm{H}$ atom positions in the X-ray measurements. According to our analysis, these transformations introduce less than one degree of systematic error. These small quantitative errors can be neglected. An alternative $\mathrm{O}-\mathrm{C}-\mathrm{O}-\mathrm{C}$ type definition, $\varphi_{\text {Fuc }}=\tau\left(\mathrm{O} 5_{\mathrm{Fuc}}-\mathrm{C} 1_{\mathrm{Fuc}}-\mathrm{O}[1,3]_{\text {link }}-\mathrm{C} 3_{\mathrm{GlcNAc}}\right)$, is also possible. The value of this angle can be obtained using the $\varphi_{\text {Fuc }}=\tau 1_{\text {Fuc }}-240^{\circ}$ equation. A similar equation is valid for $\varphi_{\mathrm{Gal}} . \psi_{\mathrm{Fuc}}=\tau 3_{\mathrm{GlcNAc}}$ and $\psi_{\mathrm{Gal}}=\tau 4_{\mathrm{GlcNAc}}$ corresponds to the notation used in ref 25 .

Once the torsion angles are on a common basis, the essential differences between the solution (NMR), solid phase (X-ray), and gas phase (our isolated models) can be considered. In the liquid and solid phases, the solvent and crystal field constitute strong intermolecular forces that can influence the molecular geometry. An important difference is that the calculations are able to identify the various rotamers of the conformational space, while NMR experiments provide only average structures. If there is agreement between the solid-, liquid-, and the most stable gas-phase structures, it is likely that the structure is rigid relative to the forces that distort the molecule in the condensed phases. Analysis of the bound structures can reveal some details of the binding, and again the degree of discrepancy between the free and bound structures may provide hints about the forces that distort the molecule in the bound state.
Table 1 shows the linkage torsion angles of $\mathrm{Le}^{\mathrm{x}}$ and $\mathrm{sLe}^{\mathrm{x}}$ as measured by X-ray diffraction, ${ }^{9}$ and by NOE $\mathrm{NMR}^{5}$ in both water solution and as bound to three selectins (E, P, and L). The error bars of the NMR results are also given. ${ }^{5}$ The NMR results (noted by + in Figures 3-6) are relatively precise for the solution structure of $\mathrm{SLe}^{\mathrm{x}}$, while large uncertainties $\left( \pm 10^{\circ}\right)$ occur for two of the bound conformers (cf. Table 1). The X-ray results yielded two different structures for $\mathrm{Le}^{\mathrm{x}}$ in the asymmetric unit, noted by X-ray 1 , and X-ray 2 in Table 1 , and noted by $\bullet$ in Figures 3-6. Comparison of the two X-ray structures gives an idea about the distortion effects of the crystal field and the intermolecular interactions. We note that the asymmetric unit contains nine water molecules. ${ }^{9}$ The key glycosidic torsion angles are similar in both structures. In particular, the $\tau 3_{\mathrm{GlcNAc}}$ angles agree (within $1^{\circ}$ ). However, larger differences can be observed in the $\tau 1_{\mathrm{Fuc}}\left(6.4^{\circ}\right)$ and for $\tau 1_{\mathrm{Gal}}\left(9.6^{\circ}\right)$ (cf. Table 1). The NOE NMR average structure in solution agrees quite well with the X-ray structures. With the exception of $\tau 3_{\mathrm{GlcNAc}}$ the NMR torsion angle values fall between the two corresponding $\mathrm{X}$-ray values. Even for $\tau 3_{\mathrm{GlcNAc}}$ there is only a small difference $\left(3^{\circ}\right)$ between the X-ray and solution NOE NMR values (cf. Table 1). Similar results were obtained from the X-ray study of the complex of $\mathrm{sLe}^{\mathrm{X}}$ with a modified mannose binding protein..$^{25}$

3.1.2. MM2* and ab Initio Glycosidic Torsion Angles in Le $^{\mathbf{x}}$. According to earlier MM3 molecular mechanics studies, the Fuc- $\alpha-1,3-$ GlcNAc glycosidic torsion angles in sLe ${ }^{\mathrm{x}}$ correspond to one of the two minima for the corresponding disaccharide. ${ }^{26}$ However, the fucose-galactose interaction forces the Gal- $\beta-1,4-$ GlcNAc glycosidic torsion angles out of the minima related to the corresponding disaccharide (the MM3 energy surfaces are published ref 26). The most stable conformation of $\mathrm{Le}^{\mathrm{x}}$ predicted by the earlier molecular mechanics studies is close to that obtained by NMR experiments. ${ }^{26}$ The experimental and calculated glycosidic angles correspond to a so-called "stacked" conformation for free Le $\mathrm{e}^{\mathrm{x}}$. In this arrangement the plane of the fucose ring is nearly parallel with the plane of the galactose ring. The hydrophobic side of the fucose (the $\mathrm{C} 6$ and $\mathrm{O} 5$ side) turns toward the galactose (cf. Figure 2). Databases of MM2* and HF/6-31G(d) equilibrium structures of $\mathbf{I}$ and $\mathbf{I I}$ are published in ref 27. Other rotamers can occur in the interactions with receptors, but they have considerably higher energy in the gas phase.

Figure 3 shows the distribution of the MM2* results for the 11 most stable rotamers of Le ${ }^{\mathrm{x}}$, II, in the $\tau 1_{\mathrm{Fuc}}, \tau 3_{\mathrm{GlcNAc}}, \tau 4_{\mathrm{GlcNAc}}$, and $\tau 1_{\mathrm{Gal}}$ conformational space from our earlier study ${ }^{7}$ and the experimental results. The four different NOE NMR results are noted as + soln., E, P, and L for measurements in water solution, and when bound to E-, P-, and L-selectins, respectively. Figure 4 shows the corresponding HF/6-31G(d) results and the same experimental results. The good agreement between the solidand liquid-phase structures is supplemented by a rather good agreement with the MM2* torsion angles (cf. Figure 3) and by an even better agreement with the HF/6-31G(d) torsion angles (cf. Figure 4).

Comparison of MM2*, X-ray, and NOE NMR solution torsion angles provides good agreement for $\tau 1_{\mathrm{Fuc}}$. For $\tau 3_{\mathrm{GlcNAc}}$, the MM2* values are about $10^{\circ}$ larger than experimental values (cf. Figure 3). The agreement between MM2* and experimental values of $\tau 4_{\mathrm{GlcNAc}}$ is again very good. For $\tau 1_{\mathrm{Gal}}$, the MM2* values are too large again, $\sim 175^{\circ}$ (cf. Figure 3 ). The ab initio torsion angles agree considerably better with the experimental results (cf. Figure 4). Another essential difference between the MM2* and ab initio results is that the latter provide better 


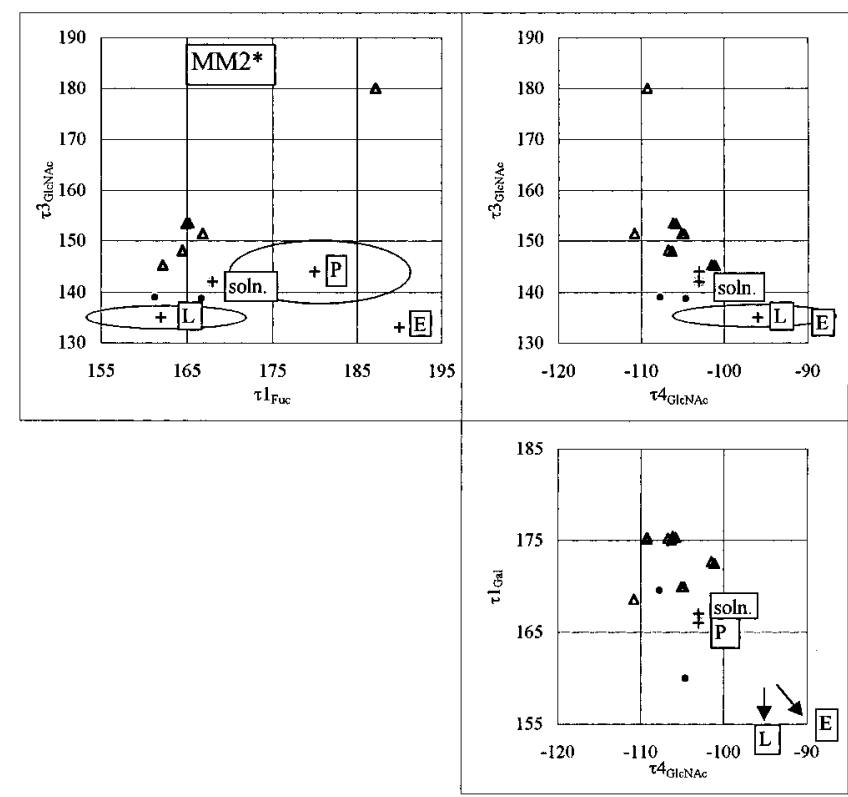

Figure 3. Distribution of the 11 most stable rotamers of $\mathrm{Le}^{\mathrm{x}} \mathbf{I I}$ in the $\tau 1_{\mathrm{Fuc}}, \tau 3_{\mathrm{GlcNAc}}, \tau 4_{\mathrm{GlcNAc}}$, and $\tau 1_{\mathrm{Gal}}(\mathrm{deg})$ conformational space calculated with the MM2* method (noted by $\triangle$, cf. ref 7). Two $\bullet$ denote the corresponding torsion angles in the X-ray structures (cf. ref 9). The + denote the corresponding torsion angles in the NMR structures (ref 5), soln., denotes the free $\mathrm{sLe}^{\mathrm{x}}$, and $\mathrm{L}, \mathrm{P}$, and $\mathrm{E}$ denote the $\mathrm{SLe}^{\mathrm{x}}$ bound to L-, P-, and E-selectins. The ellipses represent the uncertainties in the NOE NMR results.
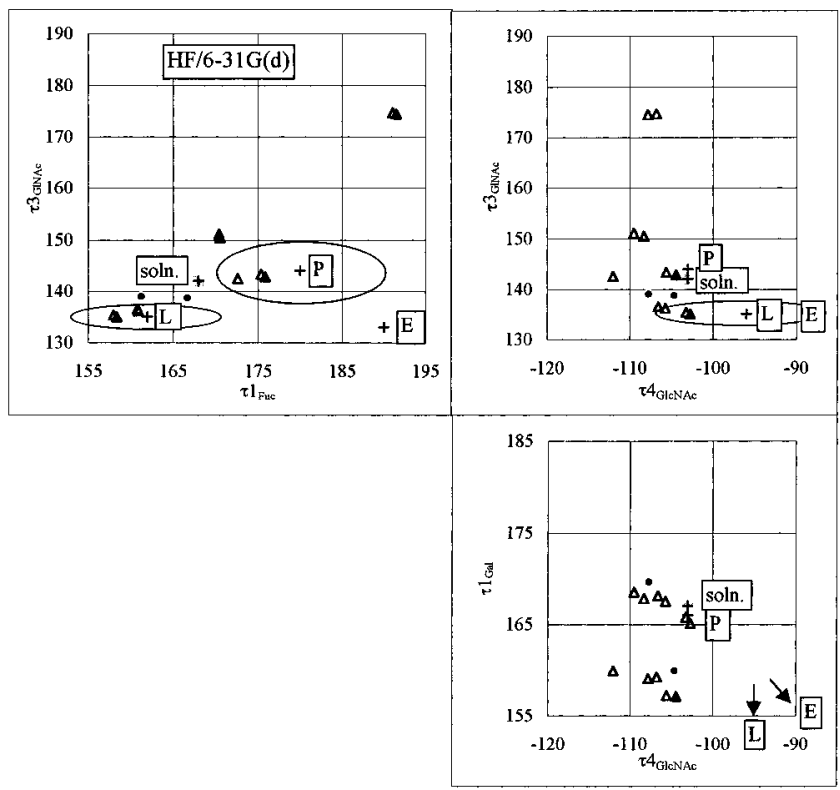

Figure 4. Distribution of the 11 most stable rotamers of Le ${ }^{\mathrm{x}} \mathbf{I I}$ in the $\tau 1_{\mathrm{Fuc}}, \tau 3_{\mathrm{GlcNAc}}, \tau 4_{\mathrm{GlcNAc}}$, and $\tau 1_{\mathrm{Gal}}(\mathrm{deg})$ conformational space calculated with the HF/6-31G(d) method (noted by $\Delta$, cf. ref 7). Two $\bullet$ denote the corresponding torsion angles in the X-ray structures (cf. ref 9). The + denote the corresponding torsion angles in the NMR structures (ref 5), soln., denotes the free sLe ${ }^{\mathrm{x}}$, and $\mathrm{L}, \mathrm{P}$, and $\mathrm{E}$ denote the $\mathrm{sLe}^{\mathrm{x}}$ bound to L-, P-, and E-selectins. The ellipses represent the uncertainties in the NOE NMR results.

differentiation of the rotamers. For example, most of the MM2* torsion angle values for $\tau 1_{\text {Fuc }}$ are clustered around $165^{\circ} \pm 3^{\circ}$ (cf. Figure 3 ). The ab initio values show a larger variation. One group (four rotamers) is clustered around $160^{\circ} \pm 2^{\circ}$, very close to $\tau 1_{\text {Fuc }}$ in the sLe ${ }^{\mathrm{x}} \mathrm{L}$-selectin complex, and to one of the X-ray values $\left(161.3^{\circ}\right)$. Another group of points is clustered around $172^{\circ} \pm 3^{\circ}$, close to the solution structure and to the other X-ray value $\left(166.7^{\circ}\right)$ (cf. Figure 4$)$. In two of the other low-energy MM2* and HF/6-31G(d) rotamers the value of $\tau 1_{\text {Fuc }}$ is about $185^{\circ}$. This value corresponds to the preferred exoanomeric position and it is between the experimental values for $\mathrm{sLe}^{\mathrm{x}}$ bound to $\mathrm{E}$ - and $\mathrm{P}$-selectins. However, in the same low-energy rotamers the calculated $\tau 3_{\mathrm{GlcNAc}} \approx 180^{\circ}$. This value is quite different from the bound NMR values of $133^{\circ}-144^{\circ}$. In this latter orientation, the fucose moiety is rotated toward the galactose moiety, resulting in a forced "stacked" arrangement. This structure is not stable in the free $\mathrm{Le}^{\mathrm{x}}$ (vide infra).

In $\mathrm{sLe}^{\mathrm{x}}$ bound to E-selectin the Gal- $\beta-1,4-\mathrm{GlcNAc}$ and Fuc$\alpha-1,3-$ GlcNAc linkages are distorted considerably (together with the NeuAc- $\alpha-2,3-G a l-\beta-1,4$ linkage,${ }^{5}$ not studied here). Linear dependence for $\tau 1_{\text {Fuc }}$ vs $\tau 3_{\text {GlcNAc }}$ can be observed in Figure 4 (cf. ab initio results, $\tau 3_{\mathrm{GlcNAc}} \approx 1.13 \tau 1_{\mathrm{Fuc}}-47^{\circ}$ ). This suggests that the glycosidic linkage conformation found in the $\mathrm{sLe}^{\mathrm{x}}-\mathrm{E}$ selectin complex, characterized by $\tau 1_{\text {Fuc }} \approx 190^{\circ}$ and $\tau 3_{\mathrm{GlcNAc}}$ $\approx 133^{\circ}$, is not particularly stable in the unbound $\mathrm{SLe}^{\mathrm{x}}$. The ab initio calculations suggest torsion angle pairs of $\tau 1_{\mathrm{Fuc}} \approx 190^{\circ}$ and $\tau 3_{\mathrm{GlcNAc}} \approx 168^{\circ}$ or $\tau 1_{\mathrm{Fuc}} \approx 160^{\circ}$ and $\tau 3_{\mathrm{GlcNAc}} \approx 133^{\circ}$ torsion angle pairs. The distortion of the Gal- $\beta-1,4-\mathrm{GlcNAc}$ linkage is so large that the corresponding central points are outside the ranges of Figures 3 and 4 . The $\mathrm{sLe}^{\mathrm{x}}$ is relatively strongly bound to E-selectin according to the measurement of the equilibrium binding-constant $\left(K_{\mathrm{D}} \approx 0.72 \mathrm{mM}\right.$ at $\left.300 \mathrm{~K}\right) .{ }^{5}$ This strong binding distorts the glycosidic linkages considerably relative to the free (gas or liquid phase) structures.

In sLe ${ }^{\mathrm{x}}$ bound to $\mathrm{P}$-selectin $\left(K_{\mathrm{D}} \approx 7.8 \mathrm{mM}\right.$ at $\left.300 \mathrm{~K}\right),{ }^{5}$ the conformations of the two glycosidic linkages of $\mathrm{Le}^{\mathrm{x}}$ change only slightly, mostly in the $\tau 1_{\text {Fuc }}$ torsion. The $K_{\mathrm{D}}$ value shows that the binding is very weak between $\mathrm{sLe}^{\mathrm{x}}$ and $\mathrm{P}$-selectin. This weak interaction is not sufficient to distort the relatively rigid $\mathrm{Le}^{\mathrm{x}}$ part of $\mathrm{sLe}^{\mathrm{x}}$ very much.

In $\mathrm{sLe}^{\mathrm{x}}$ bound to L-selectin $\left(K_{\mathrm{D}} \approx 3.9 \mathrm{mM}\right.$ at $\left.300 \mathrm{~K}\right),{ }^{5}$ the orientation of the Fuc- $\alpha-1,3-$ GlcNAc linkage of Le $^{\mathrm{x}}$ does not change relative to the most stable gas-phase structures (cf. Table 1 and Figure 3). Considerable distortion of the Gal- $\beta-1,4-$ GlcNAc linkage can be observed; however, the extent is smaller than in $\mathrm{sLe}^{\mathrm{x}}$ bound to E-selectin.

In summary, in the strongly bound sLe $\mathrm{e}^{\mathrm{x}}-\mathrm{E}$-selectin complex, both glycosidic linkage (four glycosidic torsions) were distorted considerably. In the less strongly bound sLe $\mathrm{e}^{\mathrm{x}}-\mathrm{L}$-selectin complex, only the Gal- $\beta-1,4-$ GlcNAc linkage (two glycosidic torsions) was distorted. In the weakly bound $\mathrm{sLe}^{\mathrm{x}}-\mathrm{P}$-selectin complex, only a single glycosidic torsion angle $\left(\tau 1_{\text {Fuc }}\right)$ was slightly distorted (by $\sim 10^{\circ}$, cf. Table 1 ).

3.1.3. MM2* Torsion Angles in $\operatorname{Le}^{\mathrm{x}}$ Analogues. The linkages connecting the cyclohexanediol and the 1,2-ethanediol to fucose and galactose are characterized by $\tau 1_{\text {Fuc }}, \tau 1_{\text {diol }}, \tau 2_{\text {diol }}$, and $\tau 1_{\text {Gal }}$ torsions. The definitions of $\tau 1_{\text {Fuc }}$ and $\tau 1_{\text {Gal }}$ are maintained in $\mathrm{Le}^{\mathrm{x}}$ analogues III and IV. However, because of the missing components of the GlcNAc residue, the $\tau 3_{\mathrm{GlcNAc}}$ and $\tau 4_{\mathrm{GlcNAc}}$ torsions of $\mathrm{Le}^{\mathrm{x}}$, II must be redefined as $\tau 1_{\text {diol }}$ and $\tau 2_{\text {diol }}$ torsions in $\mathrm{Le}^{\mathrm{x}}$ analogues III and IV: $\tau 1_{\text {diol }}=\tau\left(\mathrm{C}_{\mathrm{Fuc}}-\right.$ $\left.\mathrm{O}[1,1]-\mathrm{C} 1_{\text {diol }}-\mathrm{C} 2_{\text {diol }}\right) \cdot \tau 2_{\text {diol }}=\tau\left(\mathrm{C} 1_{\mathrm{Gal}}-\mathrm{O}[1,2]-\mathrm{C} 2_{\text {diol }}-\mathrm{C} 3_{\text {diol }}\right)$ in III (cf. Table 2), and $\tau 2_{\text {diol }}=\tau\left(\mathrm{C} 1_{\mathrm{Gal}}-\mathrm{O}[1,2]-\mathrm{C} 2_{\text {diol }}-\mathrm{C} 1_{\text {diol }}\right)$ $-240^{\circ}$ in IV (cf. Table 3).

Figure 5 shows the distribution of the 10 most stable rotamers of III and IV in the $\tau 1_{\text {Fuc }}, \tau 1_{\text {diol }}, \tau 2_{\text {diol }}$, and $\tau 1_{\text {Gal }}$ conformational space, as calculated with MM2* (cf. Tables 2 and 3). The abovementioned experimental results shown in Figure 3 are also shown in Figure 5 for reference. Databases of MM2* and HF/ 6-31G(d) equilibrium structures of III and IV are published in ref 28 . 
TABLE 2: MM2* Energies $(E)$, Relative Energies $(\Delta E)$, and $\mathrm{C}-\mathrm{C}-\mathrm{O}-\mathrm{R}$ Torsion Angles in the Most Stable Conformers of the MM2*-SUMM Conformational Search for III

\begin{tabular}{|c|c|c|c|c|c|c|c|c|c|c|c|c|c|c|}
\hline \multirow[b]{2}{*}{ no. } & \multirow{2}{*}{$\begin{array}{c}E \\
(\mathrm{~kJ} / \mathrm{mol}) \\
\end{array}$} & \multirow{2}{*}{$\begin{array}{c}\Delta E \\
(\mathrm{kcal} / \mathrm{mol})\end{array}$} & \multicolumn{2}{|c|}{$\begin{array}{c}\mathrm{C}-\mathrm{C}-\mathrm{O}-\mathrm{R} \text { torsion } \\
\text { angles (deg) in } \\
\text { cyclohexanediol }^{a}\end{array}$} & \multicolumn{6}{|c|}{$\begin{array}{c}\mathrm{C}-\mathrm{C}-\mathrm{O}-\mathrm{R} \text { torsion } \\
\text { angles }(\mathrm{deg}) \\
\text { in } \mathrm{Gal}^{a}\end{array}$} & \multicolumn{4}{|c|}{$\begin{array}{c}\mathrm{C}-\mathrm{C}-\mathrm{O}-\mathrm{R} \text { torsion } \\
\text { angles }(\mathrm{deg}) \\
\text { in } \mathrm{Fuc}^{a}\end{array}$} \\
\hline & & & $\tau 1_{\text {diol }}^{b}$ & $\tau 2_{\text {diol }^{c}}^{c}$ & $\tau 1_{\mathrm{Gal}} d$ & $\tau 2_{\mathrm{Gal}}$ & $\tau 3_{\mathrm{Gal}}$ & $\tau 4_{\mathrm{Gal}}$ & $\tau 5_{\mathrm{Gal}}$ & $\tau 6_{\mathrm{Gal}}$ & $\tau 1_{\text {Fuc }} e$ & $\tau 2_{\text {Fuc }}$ & $\tau 3_{\mathrm{Fuc}}$ & $\tau 4_{\text {Fuc }}$ \\
\hline 1 & -255.31 & 0.00 & 176.4 & -106.9 & 178.3 & -176.7 & -170.4 & -165.8 & -56.2 & -44.6 & -178.0 & -57.6 & 168.5 & 167.5 \\
\hline 2 & -251.10 & 1.01 & 172.4 & -115.3 & -178.3 & -176.4 & -170.5 & -168.5 & 50.4 & -71.2 & -177.3 & 59.2 & -95.9 & 170.6 \\
\hline 3 & -248.91 & 1.53 & 162.9 & -98.5 & 164.3 & -177.4 & -170.4 & -163.5 & -64.5 & -45.5 & 174.0 & 53.8 & -89.3 & 169.7 \\
\hline 4 & -247.55 & 1.85 & 149.0 & -92.6 & 171.4 & -175.4 & -169.6 & -166.2 & -56.2 & -41.0 & 161.2 & -77.3 & 171.8 & 168.2 \\
\hline 5 & -245.91 & 2.25 & -62.2 & -110.6 & 175.8 & -174.8 & -170.3 & -163.8 & -58.4 & -60.3 & 155.2 & 176.9 & 167.1 & 166.9 \\
\hline 6 & -245.63 & 2.31 & 176.7 & -110.1 & 175.6 & -177.0 & -169.7 & -167.8 & 59.2 & 173.6 & -179.1 & -76.8 & 172.6 & 167.9 \\
\hline 7 & -245.24 & 2.4 & 152 & -100.8 & 173.6 & -174.5 & -169 & -16 & 53.3 & -5 & 163.6 & -79.0 & 170.3 & 168.8 \\
\hline 8 & -244.97 & 2.47 & 175. & -112.4 & 177.4 & -176.5 & -170.0 & -167.8 & 53.2 & -71.0 & -177.3 & 162.1 & 176.7 & 168.3 \\
\hline 9 & -244.32 & 2.63 & 167.9 & -112.2 & -179.9 & -174.8 & -170.4 & -168.0 & 47.9 & -24.9 & 179.4 & -72.1 & 170.7 & 167.4 \\
\hline 10 & -244.32 & 2.63 & 173.3 & -111.8 & 176.2 & -176.7 & -170.0 & -168.1 & 54.0 & -70.3 & -178.9 & 52.7 & 36.0 & 29.2 \\
\hline
\end{tabular}

${ }^{a}$ The numbers of the atoms are based on standard carbohydrate nomenclature for glucose rings (cf. Figure 1). $\tau n=\tau(\mathrm{C}(n+1)-\mathrm{C} n-\mathrm{O}-\mathrm{R})$ where $\mathrm{R}=\mathrm{C}$ or $\mathrm{H}$ and $n=1,2,3,4 . \tau 5=\tau(\mathrm{O}-\mathrm{C} 5-\mathrm{C} 6-\mathrm{O}), \tau 6=\tau(\mathrm{C} 5-\mathrm{C} 6-\mathrm{O}-\mathrm{H})(\mathrm{cf}$. Figure 2$)$. To facilitate the overview, the torsion angles differing more than $\pm 6^{\circ}$ from the value in the first row are set in bold. ${ }^{b} \tau 1_{\text {diol }}=\tau\left(\mathrm{C} 1_{\text {Fuc }}-\mathrm{O}[1,3]_{\text {link }}-\mathrm{C} 1_{\text {diol }}-\mathrm{C} 2_{\text {diol }}\right) \cdot{ }^{c} \tau 2_{\text {diol }}=\tau\left(\mathrm{C} 1_{\text {Gal }}-\mathrm{O}[1,2]_{\text {link }}-\right.$ $\left.\mathrm{C} 2_{\text {diol }}-\mathrm{C} 3_{\text {diol }}\right) .{ }^{d} \tau 1_{\text {Gal }}=\tau\left(\mathrm{C} 2_{\text {Gal }}-\mathrm{C} 1_{\text {Gal }}-\mathrm{O}[1,2]_{\text {link }}-\mathrm{C} 2_{\text {diol }}\right) .{ }^{e} \tau 1_{\text {Fuc }}=\tau\left(\mathrm{C} 2_{\text {Fuc }}-\mathrm{C} 1_{\text {Fuc }}-\mathrm{O}[1,1]_{\text {link }}-\mathrm{C} 1_{\text {diol }}\right)$.

TABLE 3: MM2* Energies $(E)$, Relative Energies $(\Delta E)$, and $\mathrm{C}-\mathrm{C}-\mathrm{O}-\mathrm{R}$ Torsion Angles in the Most Stable Conformers of the MM2*-SUMM Conformational Search for IV

\begin{tabular}{|c|c|c|c|c|c|c|c|c|c|c|c|c|c|c|}
\hline \multirow[b]{2}{*}{ no. } & \multirow{2}{*}{$\begin{array}{c}E \\
(\mathrm{~kJ} / \mathrm{mol}) \\
\end{array}$} & \multirow{2}{*}{$\begin{array}{c}\Delta E \\
(\mathrm{kcal} / \mathrm{mol})\end{array}$} & \multicolumn{2}{|c|}{$\begin{array}{c}\mathrm{C}-\mathrm{C}-\mathrm{O}-\mathrm{R} \text { torsion } \\
\text { angles (deg) } \\
\text { in ethanediol }{ }^{a}\end{array}$} & \multicolumn{6}{|c|}{$\begin{array}{c}\mathrm{C}-\mathrm{C}-\mathrm{O}-\mathrm{R} \text { torsio } \\
\text { angles }(\mathrm{deg}) \\
\text { in } \mathrm{Gal}^{a}\end{array}$} & \multicolumn{4}{|c|}{$\begin{array}{c}\mathrm{C}-\mathrm{C}-\mathrm{O}-\mathrm{R} \text { torsion } \\
\text { angles }(\mathrm{deg}) \\
\text { in } \mathrm{Fuc}^{a}\end{array}$} \\
\hline & & & $\tau 1_{\text {diol }^{b}}^{b}$ & $\tau 2_{\text {diol }^{c}}^{c}$ & $\tau 1_{\mathrm{Gal}^{d}}$ & $\tau 2_{\text {Gal }}$ & $\tau 3_{\text {Gal }}$ & $\tau 4_{\mathrm{Gal}}$ & $\tau 5_{\mathrm{Gal}}$ & $\tau 6_{\mathrm{Gal}}$ & $\tau 1_{\text {Fuc }}^{e}$ & $\tau 2_{\text {Fuc }}$ & $\tau 3_{\text {Fuc }}$ & $\tau 4_{\text {Fuc }}$ \\
\hline 1 & -281.50 & 0.00 & -174.3 & 10 & 79.2 & 176.2 & 3 & 5.0 & 55.3 & 4.1 & 76.4 & 58.9 & 169.6 & 167.4 \\
\hline 2 & -276 & & -67.6 & -8 & & -174.5 & -170.3 & -164.1 & -58.0 & 2 & 161.4 & -179.6 & 167.2 & 167.3 \\
\hline 3 & -275.54 & 1.42 & 177.4 & -117.9 & -177.2 & -176.5 & -170.5 & -167.9 & 51.3 & -71.6 & 178.2 & 59.2 & -95.1 & 170.3 \\
\hline 4 & -275.50 & 1.43 & -79.9 & -71.5 & 167.0 & -52.1 & -36.3 & 61.0 & -62.3 & 63.6 & 150.0 & -83.9 & 170.2 & 168.8 \\
\hline 5 & -273.20 & 1.98 & -85.4 & -80.4 & 166.4 & -174.2 & -170.0 & -168.3 & 57.7 & -71.0 & 154.3 & -79.5 & 168.9 & 168.7 \\
\hline 6 & -273.18 & 1.99 & 167.0 & -100.3 & 167.0 & -177.2 & -170.5 & -163.5 & -64.4 & -44.7 & 174.9 & 53.8 & -88.9 & 169.8 \\
\hline 7 & -271.33 & 2.43 & 153.0 & -91.3 & 172.3 & -174.9 & -169.6 & -166.3 & -55.8 & -40.9 & 164.5 & -77.4 & 171.6 & 168.3 \\
\hline 8 & -271.19 & 2.46 & -175.8 & -112.9 & 177.0 & -176.7 & -169.6 & -167.8 & 60.3 & 173.3 & 175.5 & -77.1 & 171.2 & 168.1 \\
\hline 9 & -270.45 & 2.64 & -177.7 & -115.3 & 178.9 & -176.2 & -170.0 & -167.7 & 54.1 & -71.9 & 177.9 & 160.7 & 175.6 & 168.4 \\
\hline 10 & -270.12 & 2.72 & -178.7 & -114.6 & 177.8 & -176.4 & -170.0 & -168.0 & 55.2 & -71.0 & 176.6 & 52.5 & 35.9 & 29.4 \\
\hline
\end{tabular}

${ }^{a}$ The numbers of the atoms are based on standard carbohydrate nomenclature for glucose rings (cf. Figure 1$) . \tau n=\tau(\mathrm{C}(n+1)-\mathrm{C} n-\mathrm{O}-\mathrm{R})$, where $\mathrm{R}=\mathrm{C}$ or $\mathrm{H}$ and $n=1,2,3,4 . \tau 5=\tau(\mathrm{O}-\mathrm{C} 5-\mathrm{C} 6-\mathrm{O}), \tau 6=\tau(\mathrm{C} 5-\mathrm{C} 6-\mathrm{O}-\mathrm{H})$ (cf. Figure 2). To facilitate the overview, the torsion angles differing more than $\pm 6^{\circ}$ from the value in the first row are set in bold. ${ }^{b} \tau 1_{\text {diol }}=\tau\left(\mathrm{C}_{\text {Fuc }}-\mathrm{O}[1,3]_{\text {link }}-\mathrm{C} 1_{\text {diol }}-\mathrm{C} 2_{\text {diol }}\right){ }^{c} \tau 2_{\text {diol }}=\tau\left(\mathrm{C} 1_{\text {Gal }}-\mathrm{O}[1,2]_{\text {link }}-\right.$ $\left.\mathrm{C} 2_{\text {diol }}-\mathrm{C} 1_{\text {diol }}\right)-240^{\circ} .{ }^{d} \tau 1_{\text {Gal }}=\tau\left(\mathrm{C} 2_{\text {Gal }}-\mathrm{C} 1_{\text {Gal }}-\mathrm{O}[1,2]_{\text {link }}-\mathrm{C} 2_{\text {diol }}\right) .{ }^{e} \tau 1_{\text {Fuc }}=\tau\left(\mathrm{C} 2_{\text {Fuc }}-\mathrm{C} 1_{\text {Fuc }}-\mathrm{O}[1,1]_{\text {link }}-\mathrm{C} 1_{\text {diol }}\right)$.

Comparison of the MM2* results in Figures 5 and 3 shows that the lack of the NAc group close to the fucose moiety changes the distribution of the rotamers in the $\tau 1_{\text {Fuc }}-\tau 1_{\text {diol }}$ space considerably. In III and especially in IV, the preferred exoanomeric position $\left(\tau 1_{\mathrm{Fuc}} \approx 180^{\circ}\right)$ is much more populated by the low-energy rotamers, and only a few, one or two, rotamers take the $\tau 1_{\mathrm{Fuc}} \approx 165^{\circ}$ position (populated in Le , cf. Figure 3 ). Figure 5 also shows an approximate linear dependence between $\tau 1_{\text {Fuc }}$ and $\tau 1_{\text {diol }}$ similar to $\tau 1_{\text {Fuc }}$ vs $\tau 3_{\text {GlcNAc }}$ dependence (cf. Figures 3 and 4).

Inspection of the torsion angles in Table 2 shows that $\tau 1_{\text {diol }}$ values fall in groups with centers of $175^{\circ}$ ( 5 rotamers, the most stable rotamer is included), $165^{\circ}$ (two rotamers), $150^{\circ}$ (two rotamers), and $-60^{\circ}$ (single rotamer). The latter value (not shown in Figure 5 and occurring in rotamer 5 in Table 2) signals a large departure from the stacked conformation observed in II. This nonstacked rotamer occurs only once among the rotamers of III, and it is not particularly stable $(\Delta E=2.3 \mathrm{kcal} /$ mol, cf. rotamer 5 in Table 2). However, such rotamers are more frequent for IV (e.g., rotamers 2, 4, and 5 in Table 3 with center of $-70^{\circ}-80^{\circ}$ for $\tau 1_{\text {Fuc }}$ ). This clearly shows that while the conformational space of III is fairly similar to that of I and II, the conformational space of IV is rather different.

Besides the already discussed glycosidic torsion angles, the orientation hydroxyl groups (from $\tau 2$ to $\tau 4$ ) and the hydroxy- methylene group ( $\tau 5$ and $\tau 6$ ) are also shown in the Tables 2 and 3. The 12 torsion angles shown in the Tables 2 and 3 uniquely characterize the rotamers of the $\mathrm{Le}^{\mathrm{x}}$ analogues. In order to simplify the overview, we use letter codes for the values of the torsion angles. The typical interaction-free values for a torsion angle are $60^{\circ},-60^{\circ}$, and $180^{\circ}$ and we use for these values the $\mathrm{g}+, \mathrm{g}-$, and $\mathrm{t}$ letter codes, respectively. Interactionfree values rarely occur in sugars; however, within $\pm 15^{\circ}$ we use the same letter. For the three interaction-free values of $\tau 5(\mathrm{O} 5-\mathrm{C} 5-\mathrm{C} 6-\mathrm{O} 6)$ torsion angle of the hydroxymethylene group, we use capital letters: $\mathrm{G}+, \mathrm{G}^{-}$, and $\mathrm{T}$, respectively (other authors use two letter gt, gg, and tg codes for this single orientation). ${ }^{5}$ For all the other torsions, we use lower case letters. In the most stable rotamers for the galactose and fucose residues of $\mathrm{Le}^{\mathrm{x}}$ and $\mathrm{Le}^{\mathrm{x}}$ analogues, long intramolecular chains of hydrogen-bonded hydroxyl groups are formed in counterclockwise or clockwise directions as viewed from the $\beta$ face of the anomeric carbon atom. Similar patterns were found for monosaccharides earlier by French et al., and Tran and Brady ${ }^{29}$ using molecular modeling techniques, by Cramer and Truhlar using AM1 and PM3 methods, ${ }^{30}$ and by Polavarapu et al. ${ }^{31}$ at the HF/ 4-31G level of theory for D-glucose. In the fucose and in galactose residues of $\mathrm{Le}^{\mathrm{x}}$, only the anomeric $\mathrm{OH}$ group is substituted, and thus the remaining $\mathrm{OH}$ groups might show the typical orientations characteristic for the most stable monomers. 


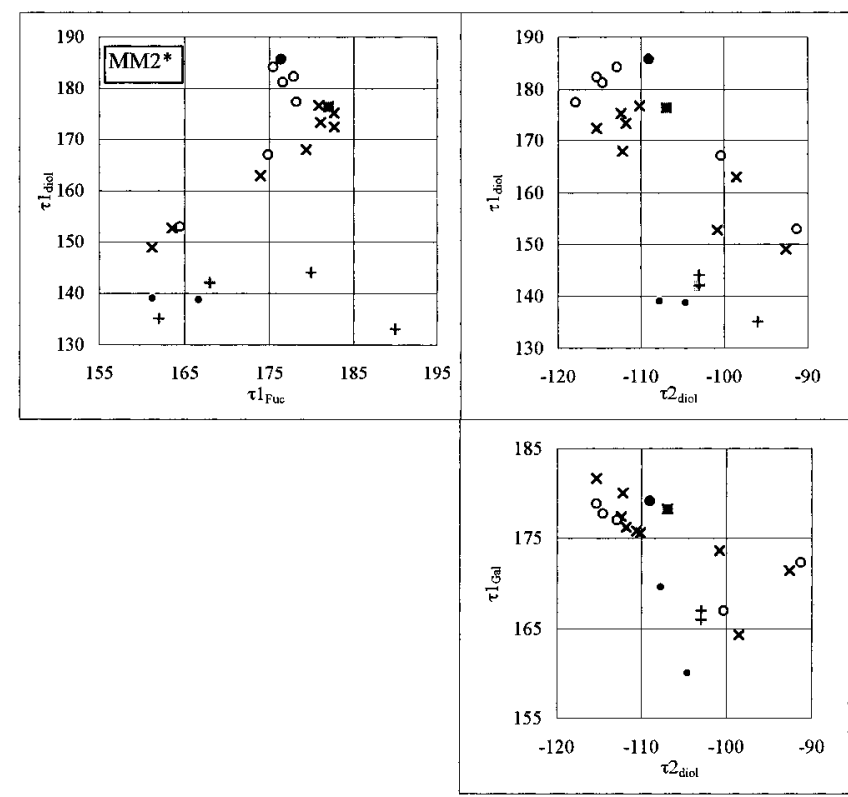

Figure 5. Distribution of the 10 most stable rotamers of III noted by $\times$ and IV noted by $\bigcirc$ in the $\tau 1_{\text {Fuc }}, \tau 1_{\text {diol }}, \tau 2_{\text {diol }}$, and $\tau 1_{\text {Gal }}$ (deg) conformational space calculated with the MM2* method. $\tau 1_{\text {diol }}$ in III and IV corresponds to $\tau 3_{\mathrm{GlcNAc}}$ in II. $\tau 2_{\text {diol }}$ in III and IV corresponds to $\tau 4_{\mathrm{GlcNAc}}$ in II. Two $\bullet$ denote the corresponding torsion angles in the $\mathrm{X}$-ray structures (cf. ref 9). The + denote the corresponding torsion angles in the NMR structures (ref 5, cf. Table 1).

Torsion Angles in the Galactose Moiety. The most stable rotamer of the Gal can be coded as $\mathrm{t} \mathrm{t} \mathrm{t} \mathrm{t} \mathrm{G-} \mathrm{g}-$ in III and IV (cf. rotamer 1, Tables 2 and 3; for $\tau 5$ we use capital letters). The order of the letters follows the order of the torsion angles. The first $t$ denotes the anti $\left(180^{\circ}\right)$ position of the first, torsion angle $\tau 1$ in galactose, etc. In the most stable MM2* structure, the hydroxyls of the hydrogen-bonded chain of galactose point in the counterclockwise direction. 19 out 20 most stable rotamers of III and IV show this counterclockwise pattern (cf. Tables 2 and 3). The only exception is rotamer 4 of $\mathbf{I V}$ in Table 3. In this rotamer, the hydroxyl groups of galactose point in the clockwise direction (the corresponding code: $\mathrm{tg}-\mathrm{g}-\mathrm{g}+\mathrm{G}-$ $\mathrm{g}+$ ). The orientation of the hydroxymethylene group changes without large influence on the relative energy (vide infra). The orientations of the hydroxymethylene group in Tables 2 and 3 are the following: $\mathrm{G}-\mathrm{g}-, \mathrm{G}+\mathrm{g}-, \mathrm{G}+\mathrm{t}, \mathrm{G}-\mathrm{g}+$. The latter occurs only once in rotamer 4 of $\mathbf{I V}$.
Torsion Angles in the Fucose Moiety. L-Fucose has the following conformation in the most stable MM2* rotamers of $\mathrm{Le}^{\mathrm{x}}$ analogues: $\mathrm{tg}-\mathrm{t} \mathrm{t}$ (cf. rotamer 1 in Tables 2, and 3). This clockwise direction of the hydroxyls corresponds to the pattern found in the most stable ${ }^{1} \mathrm{C}_{4} \mathrm{~L}$-fucose monomer. ${ }^{10,13}$ Due to the strong donor interaction with the oxygen atom of the NAc group the $\tau 2$ torsion angle for the second $\mathrm{OH}$ group of the fucose moiety deviates considerably from $-60^{\circ}$ in $\mathrm{Le}^{\mathrm{x}}{ }^{7}$ In the analogues, this interaction is missing and $\tau 2$ is not far from $\pm 60^{\circ}$ in some of the most stable rotamers (cf. Tables 2 and 3 ).

In a recent study on carbohydrate force fields, it was pointed out that the use of MM torsional energies for glycosidic bonds is still difficult. ${ }^{32}$ In order to circumvent this problem French et al. have proposed $\mathrm{HF} / 6-31 \mathrm{G}(\mathrm{d})$ calculations of all linkage torsional energies on simplified analogues of complete disaccharides. ${ }^{33}$ This shows the potential value of the ab initio results in carbohydrate chemistry.

3.1.4. HF/6-31G(d) Torsion Angles in the Le $\mathrm{e}^{\mathrm{x}}$ Analogues. Our aim is to explore the ab initio HF/6-31G(d) conformation space of III and IV, and compare the results to those obtained for I and II. ${ }^{7}$ Comparison of the torsion angles in Tables 2 and 4 shows that the HF/6-31G(d) and MM2* results agree with each other within few degrees for the first three rotamers. Similar qualitative agreement in the geometry was observed between the MM2* and HF/6-31G(d) results for $\mathrm{Le}^{\mathrm{x}}{ }^{7}{ }^{7}$ In the most stable MM2* structures of $\mathbf{I}$ and II, the hydrogen-bonded chains of galactose (in counterclockwise direction) and fucose (in clockwise direction) are not connected. ${ }^{7}$ This is similar to the present results for the most stable $\mathrm{Le}^{\mathrm{x}}$ analogues. In contrast, the relative stability of a given rotamer varies considerably depending on the method used (vide infra). For example, the most stable HF/ 6-31G(d) structure of $\mathrm{Le}^{\mathrm{x}}$ has a long chain of seven ordered hydrogen bonds including a $\mathrm{O}_{\mathrm{Gal}} \mathrm{H} \rightarrow \mathrm{O} 3_{\text {Fuc }}$ interaction (with clockwise hydrogen-bonded chain in galactose and fucose). ${ }^{7}$ This latter long chain of hydrogen bonds cannot be found in the analogues due to the missing GlcNAc moiety.

The similarity of the HF and MM2* rotamers is not general for rotamers of III and IV. Qualitative differences between the $\mathrm{HF}$ and MM2* results can be observed for several rotamers of III and IV in Tables 4 and 5. Some of the rotamers found by the MM2*-SUMM conformational search are not stable according to the HF/6-31G(d) results. During the HF geometry optimization, the rotamers 4 and 9 of III were transformed to rotamers 1 and 7, respectively (cf. Table 4). Similarly, during the HF geometry optimization, rotamers 7 and 8 of IV were

TABLE 4: HF/6-31G(d) Energies $(E)$, Relative Energies $(\Delta E)$, and $\mathrm{C}-\mathrm{C}-\mathrm{O}-\mathrm{R}$ Torsion Angles in the Most Stable Conformers of the MM2*-SUMM Conformational Search for III

\begin{tabular}{|c|c|c|c|c|c|c|c|c|c|c|c|c|c|c|}
\hline \multirow[b]{2}{*}{ no. } & \multirow{2}{*}{$\begin{array}{c}E \\
\text { (hartrees) }\end{array}$} & \multirow{2}{*}{$\begin{array}{c}\Delta E \\
(\mathrm{kcal} / \mathrm{mol})\end{array}$} & \multicolumn{2}{|c|}{$\begin{array}{l}\mathrm{C}-\mathrm{C}-\mathrm{O}-\mathrm{R} \text { torsion } \\
\text { angles (deg) } \\
\text { in cyclohexanediol }{ }^{a}\end{array}$} & \multicolumn{6}{|c|}{$\begin{array}{c}\mathrm{C}-\mathrm{C}-\mathrm{O}-\mathrm{R} \text { torsion } \\
\text { angles }(\mathrm{deg}) \\
\text { in } \mathrm{Gal}^{a}\end{array}$} & \multicolumn{4}{|c|}{$\begin{array}{c}\mathrm{C}-\mathrm{C}-\mathrm{O}-\mathrm{R} \text { torsion } \\
\text { angles }(\mathrm{deg}) \\
\text { in } \mathrm{Fuc}^{a}\end{array}$} \\
\hline & & & $\tau 1_{\text {diol }}^{b}$ & $\tau 2_{\text {diol }^{c}}$ & $\tau 1_{\mathrm{Gal}^{d}}$ & $\tau 2_{\mathrm{Gal}}$ & $\tau 3_{\mathrm{Gal}}$ & $\tau 4_{\mathrm{Gal}}$ & $\tau 5_{\mathrm{Gal}}$ & $\tau 6_{\mathrm{Gal}}$ & $\tau 1_{\text {Fuc }}^{e}$ & $\tau 2_{\text {Fuc }}$ & $\tau 3_{\text {Fuc }}$ & $\tau 4_{\mathrm{Fuc}}$ \\
\hline 1 & -1523.70664 & 0.00 & 167.6 & -1 & 70.4 & -178.6 & 2 & 168.3 & 53.7 & -48.9 & -178.1 & -60.3 & 173.4 & 167.0 \\
\hline 2 & 3 & & & & & .9 & & 3 & & & 3.3 & 61.3 & & 57.5 \\
\hline 3 & -152 & 8 & 158.7 & -100.3 & 156.4 & -178.2 & -169.9 & -167.2 & -59.9 & -4 & 175.9 & 49.3 & -92.7 & 164.8 \\
\hline $4 \rightarrow 1$ & -152 & 0 & & & & & & & & & & & & \\
\hline 5 & -1523.70218 & 2.80 & -67.6 & -88.8 & 173.7 & -177.7 & -168.8 & -165.1 & -53.7 & -59.9 & 154.6 & 169.3 & 165.4 & 165.6 \\
\hline 6 & -1523.70566 & 0.61 & -125.5 & -97.2 & 163.9 & -178.0 & 189.4 & -169.1 & 63.0 & -8 & 162.5 & -73.3 & 169.2 & 169.1 \\
\hline 7 & -1523.70495 & 1.06 & 146.3 & -98.7 & 164.4 & -175.7 & -170.6 & -169.6 & 58.7 & -56.5 & 164.2 & -78.2 & 167.3 & 170.0 \\
\hline 8 & -1523.70161 & 3.16 & 169.0 & -108.2 & 164.2 & -179.1 & -170.5 & -168.8 & 59.7 & -75.5 & -177.3 & 167.8 & 173.3 & 169.7 \\
\hline $9 \rightarrow 7$ & -1523.70495 & 1.06 & & & & & & & & & & & & \\
\hline 10 & -1523.70225 & 2.76 & 170.0 & -109.8 & 165.8 & -179.4 & 188.9 & -189.7 & 59.3 & -70.4 & 179.6 & 50.6 & 38.1 & 36.1 \\
\hline
\end{tabular}

${ }^{a}$ The numbers of the atoms are based on standard carbohydrate nomenclature for glucose rings (cf. Figure 1$) . \tau n=\tau(\mathrm{C}(n+1)-\mathrm{Cn} n-\mathrm{O}-\mathrm{R})$, where $\mathrm{R}=\mathrm{C}$ or $\mathrm{H}$ and $n=1,2,3,4 . \tau 5=\tau(\mathrm{O}-\mathrm{C} 5-\mathrm{C} 6-\mathrm{O}), \tau 6=\tau(\mathrm{C} 5-\mathrm{C} 6-\mathrm{O}-\mathrm{H})$ (cf. Figure 2). To facilitate the overview the torsion angles differing more than $\pm 6^{\circ}$ from the value in the first row are set in bold. ${ }^{b} \tau 1_{\text {diol }}=\tau\left(\mathrm{C} 1_{\text {Fuc }}-\mathrm{O}[1,3]_{\text {link }}-\mathrm{C} 1_{\text {diol }}-\mathrm{C} 2_{\text {diol }}\right) .{ }^{c} \tau 2_{\text {diol }}=\tau\left(\mathrm{C} 1_{\text {Gal }}-\mathrm{O}[1,2]_{\text {link }}-\right.$

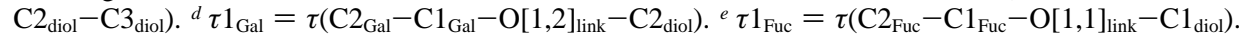


TABLE 5: HF/6-31G(d) Energies $(E)$, Relative Energies $(\Delta E)$, and $\mathrm{C}-\mathrm{C}-\mathrm{O}-\mathrm{R}$ Torsion Angles in the Most Stable Conformers of the MM2*-SUMM Conformational Search for IV

\begin{tabular}{|c|c|c|c|c|c|c|c|c|c|c|c|c|c|c|}
\hline \multirow[b]{2}{*}{ no. } & \multirow{2}{*}{$\begin{array}{c}E \\
\text { (hartrees) }\end{array}$} & \multirow{2}{*}{$\underset{(\mathrm{kcal} / \mathrm{mol})}{\Delta E}$} & \multicolumn{2}{|c|}{$\begin{array}{c}\mathrm{C}-\mathrm{C}-\mathrm{O}-\mathrm{R} \text { torsion angles } \\
(\mathrm{deg}) \\
\text { in ethanediol }^{a}\end{array}$} & \multicolumn{6}{|c|}{$\begin{array}{c}\mathrm{C}-\mathrm{C}-\mathrm{O}-\mathrm{R} \text { torsion } \\
\text { angles }(\mathrm{deg}) \\
{\text { in } \mathrm{Gal}^{a}}^{a}\end{array}$} & \multicolumn{4}{|c|}{$\begin{array}{c}\mathrm{C}-\mathrm{C}-\mathrm{O}-\mathrm{R} \text { torsion } \\
\text { angles }(\mathrm{deg}) \\
\text { in } \mathrm{Fuc}^{a}\end{array}$} \\
\hline & & & $\tau 1_{\text {diol }}^{b}$ & $\tau 2_{\text {diol }^{c}}$ & $\tau 1_{\mathrm{Gal}}{ }^{d}$ & $\tau 2_{\mathrm{Gal}}$ & $\tau 3_{\mathrm{Gal}}$ & $\tau 4_{\mathrm{Gal}}$ & $\tau 5_{\mathrm{Gal}}$ & $\tau 6_{\mathrm{Gal}}$ & $\tau 1_{\text {Fuce }}$ & $\tau 2_{\mathrm{Fuc}}$ & $\tau 3_{\text {Fuc }}$ & $\overline{\tau 4_{\text {Fuc }}}$ \\
\hline 1 & -1368.72015 & 0.00 & -174.9 & -110.2 & -179.8 & -178.2 & -170.3 & -168.1 & -51.7 & -50.3 & 175.4 & -52.3 & 164.0 & 167.0 \\
\hline 2 & -1368.71890 & 0.79 & -74.8 & -95.4 & 173.5 & -177.9 & -169.2 & -166.0 & -54.9 & -54.6 & 171.8 & 168.2 & 166.3 & 166.3 \\
\hline 3 & -1368.71701 & 1.97 & 173.8 & 57.3 & 178.6 & -178.7 & -171.7 & -167.2 & 55.3 & -78.9 & -177.9 & 61.0 & -95.3 & 167.3 \\
\hline 4 & -1368.72448 & -2.72 & -87.3 & -87.0 & 167.2 & -50.9 & -42.1 & 40.3 & -65.1 & 75.2 & 160.1 & -87.0 & 170.9 & 170.6 \\
\hline 5 & -1368.72413 & -2.50 & -97.2 & -92.7 & 165.1 & -176.7 & -170.8 & -169.4 & 63.0 & -84.8 & 156.9 & -80.2 & 167.5 & 169.5 \\
\hline 6 & -1368.71808 & 1.30 & 166.6 & -105.4 & 161.7 & -178.5 & -170.0 & -167.2 & -60.1 & -44.8 & 176.7 & 49.7 & -94.8 & 165.5 \\
\hline $7 \rightarrow 1$ & -1368.72015 & 0.00 & & & & & & & & & & & & \\
\hline $8 \rightarrow 5$ & -1368.72413 & -2.50 & & & & & & & & & & & & \\
\hline 9 & -1368.71531 & 3.04 & -176.0 & -113.4 & 169.7 & -178.7 & -170.5 & -168.8 & 61.0 & -7 & 176.6 & 164.3 & 173.6 & 170.2 \\
\hline 10 & -1368.71603 & 2.59 & -174.9 & -114.8 & 171.2 & -179.0 & -170.9 & -169.4 & 60.7 & -71.0 & 173.9 & 49.4 & 38.3 & 36.0 \\
\hline
\end{tabular}

${ }^{a}$ The numbers of the atoms are based on standard carbohydrate nomenclature for glucose rings (cf. Figure 1$) . \tau n=\tau(\mathrm{C}(n+1)-\mathrm{C} n-\mathrm{O}-\mathrm{R})$, where $\mathrm{R}=\mathrm{C}$ or $\mathrm{H}$ and $n=1,2,3,4 . \tau 5=\tau(\mathrm{O}-\mathrm{C} 5-\mathrm{C} 6-\mathrm{O}), \tau 6=\tau(\mathrm{C} 5-\mathrm{C} 6-\mathrm{O}-\mathrm{H})$ (cf. Figure 2). To facilitate the overview, the torsion angles differing more than $\pm 6^{\circ}$ form the value in the first row are set in bold. ${ }^{b} \tau 1_{\text {diol }}=\tau\left(\mathrm{C} 1_{\text {Fuc }}-\mathrm{O}[1,3]_{\text {link }}-\mathrm{C} 1_{\text {diol }}-\mathrm{C} 2_{\text {diol }}\right){ }^{c} \tau 2_{\text {diol }}=\tau\left(\mathrm{C} 1_{\text {Gal }}-\mathrm{O}[1,2]_{\text {link }}-\right.$ $\left.\mathrm{C} 2_{\text {diol }}-\mathrm{C} 1_{\text {diol }}\right)-240^{\circ} .{ }^{d} \tau 1_{\text {Gal }}=\tau\left(\mathrm{C} 2_{\text {Gal }}-\mathrm{C} 1_{\text {Gal }}-\mathrm{O}[1,2]_{\text {link }}-\mathrm{C} 2_{\text {diol }}\right) .{ }^{e} \tau 1_{\text {Fuc }}=\tau\left(\mathrm{C} 2_{\mathrm{Fuc}}-\mathrm{C} 1_{\text {Fuc }}-\mathrm{O}[1,1]_{\text {link }}-\mathrm{C} 1_{\text {diol }}\right)$.

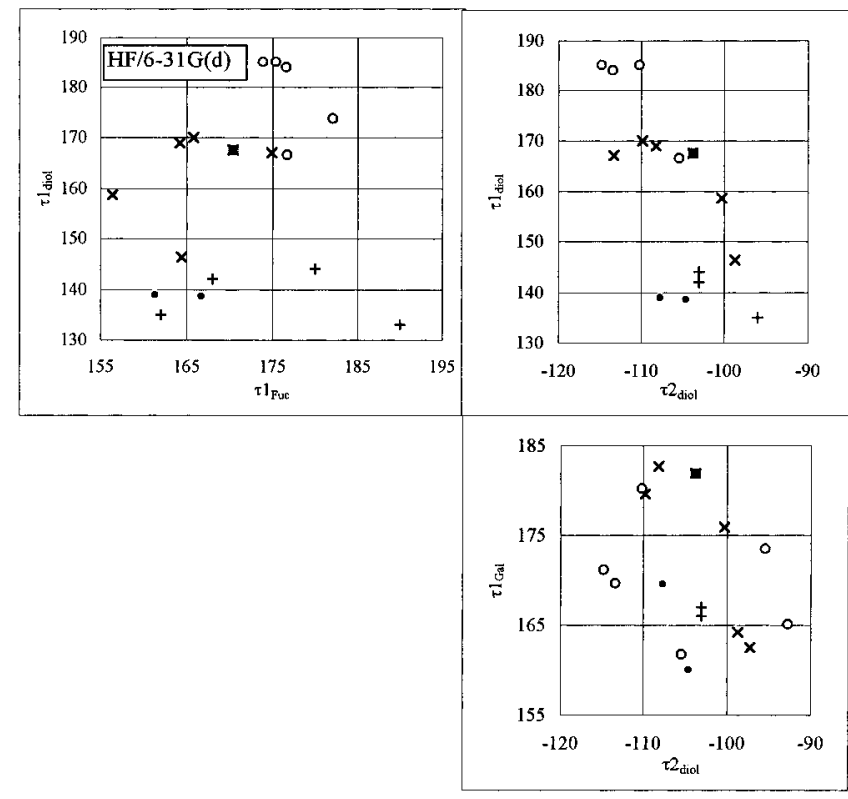

Figure 6. Distribution of the 10 most stable rotamers of III noted by $\times$ and $\mathbf{I V}$ noted by $O$ in the $\tau 1_{\text {fuc }}, \tau 1_{\text {diol }}, \tau 2_{\text {diol }}$, and $\tau 1_{\text {Gal }}$ (deg) conformational space calculated with the HF/6-31G(d) method. $\tau 1_{\text {diol }}$ in III and IV corresponds to $\tau 3_{\mathrm{GlcNAc}}$ in II. $\tau 2_{\text {diol }}$ in III and IV corresponds to $\tau 4_{\mathrm{GlcNAc}}$ in II. Two $\bullet$ denote the corresponding torsion angles in the X-ray structures (cf. ref 9). The + denote the corresponding torsion angles in the NMR structures (ref 5, cf. Table 1).

transformed to rotamers 1 and 5, respectively (cf. Table 5). Such qualitative differences were not observed in our previous work for the MM2* and HF rotamers of I and II. ${ }^{7}$

Figure 6 shows the distribution of the 10 most stable rotamers of III and IV in the $\tau 1_{\text {Fuc }}, \tau 1_{\text {diol }}, \tau 2_{\text {diol }}$, and $\tau 1_{\text {Gal }}$ conformational space calculated with HF/6-31G(d) method (cf. Tables 4 and 5). The above-mentioned experimental results are also shown in Figure 6 for reference. Comparison of the HF/6-31G(d) and MM2* results in Figures 5 and 6 shows that the HF results are somewhat closer to the experimental results. Comparison of the HF/6-31G(d) results in Figures 4 and 6 shows that the missing pieces of the NAc group close to the fucose moiety cause substantial changes in the distribution of the rotamers in the $\tau 1_{\text {Fuc }}-\tau 1_{\text {diol }}$ space. In III and especially in $\mathbf{I V}$, the $\tau 1_{\text {diol }}$ torsion angle is considerably larger than the corresponding $\tau 3_{\mathrm{GlcNAc}}$ in II. This difference is larger for the 1,2-ethanediol derivative IV.

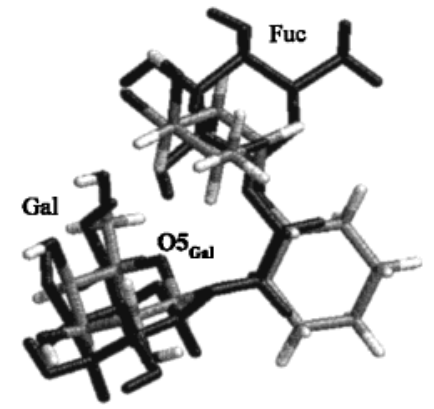

Figure 7. Comparison of the most stable conformations for III (variable gray) and IV (dark gray) calculated with $\mathrm{HF} / 6-31 \mathrm{G}(\mathrm{d})$ method.

Some of the rotamers show a nonstacked structure (e.g., rotamers 5 and 6 in Table 4, and rotamers 2, 3, 4, and 5 in Table 5). Half of the rotamers of IV are nonstacked. The most stable HF rotamer of $\mathbf{I V}$ is nonstacked (cf. rotamer 4 in Table 5). Figure 7 shows the overlap between the most stable HF conformers of III and IV. The nonstacked rotamer 5 of III is not particularly stable ( $\Delta E=2.8 \mathrm{kcal} / \mathrm{mol}$, cf. Table 4$)$. Another nonstacked rotamer of III, rotamer 6 is the second most stable $(\Delta E=0.6 \mathrm{kcal} / \mathrm{mol}$, cf. Table 4$)$. The HF geometry optimization of this rotamer was started from the MM2* structure which shows the typical stacked conformation. During the HF geometry optimization the $\tau 1_{\text {diol }}$ torsion angle was rotated from the initial $176.7^{\circ}$ to the final $-125.5^{\circ}$ value (cf. Tables 2 and 4 ) resulting a nonstacked structure. In the final HF rotamer an $\mathrm{O} 2_{\mathrm{Fuc}} \mathrm{H} \rightarrow \mathrm{O}_{\mathrm{Gal}}$ interaction is present as illustrated in Figure 8 . The preference for hydrogen bonds such as $\mathrm{O} 2_{\mathrm{Fuc}} \mathrm{H} \rightarrow \mathrm{O} 5_{\mathrm{Gal}}$ is a general feature of $\mathrm{HF} / 6-31 \mathrm{G}(\mathrm{d})$ method, and this interaction is also present in the most stable rotamer 4 of IV. Again, the HF conformational space of III is more similar to that of I and II, than it is to the conformational space of IV.

Torsion Angles in the Galactose Moiety. In the most stable rotamer of III the torsion angles $\tau 1-\tau 6$ of the galactose moiety

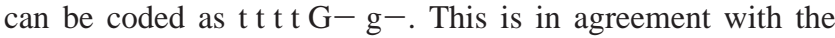
most stable MM2* structure (cf. rotamer 1 in Tables 2 and 4). The $\mathrm{OH}$ groups of the galactose point in the counterclockwise direction. Of the 16 rotamers of III and IV in Tables 4 and 5, 15 show this counterclockwise pattern. The only exception is the rotamer 4 of $\mathbf{I V}$ in Table 5. In this rotamer the $\mathrm{OH}$ groups point in the clockwise direction. This rotamer can be coded as $\mathrm{t} g-\mathrm{g}-\mathrm{g}+\mathrm{G}-\mathrm{g}+$. The essential difference between the MM2* and HF/6-31G(d) results is the relative stability of this rotamer (vide infra). The orientations of the hydroxymethylene 


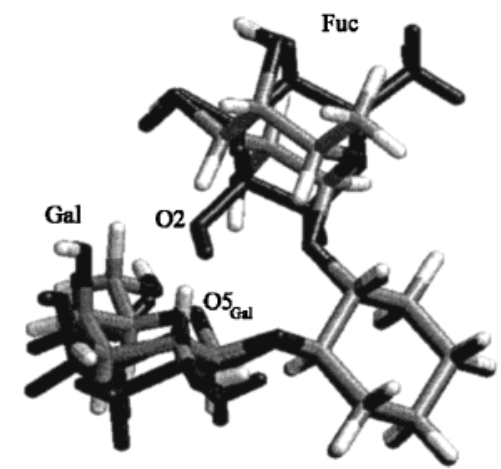

Figure 8. Comparison of the equilibrium geometry of rotamer number 6 of III calculated with MM2* (variable gray) and HF/6-31G(d) method (dark gray).

group in Tables 4 and 5 are the following: $G-g-, G+g-$, and $\mathrm{G}-\mathrm{g}+$. The latter occurs only once in rotamer 4 of IV. The $\mathrm{G}+\mathrm{t}$ rotamer of the hydroxymethylene group is missing from the HF conformational space in Tables 4 and 5. We started the geometry optimization from the MM2* structure with $\mathrm{G}+\mathrm{t}$ position, and during the HF geometry optimization this rotamer was always transformed to $\mathrm{G}+\mathrm{g}-$.

The three most stable rotamers of the isolated $\beta$-D-galactose molecule according to $\mathrm{HF} / 6-31 \mathrm{G}(\mathrm{d})$ results ${ }^{15,34}$ are (in the order of decreasing stability): $\mathrm{t} \mathrm{t} \mathrm{t} \mathrm{t} \mathrm{T} \mathrm{g+,} \mathrm{t} \mathrm{t} \mathrm{t} \mathrm{t} \mathrm{G+} \mathrm{g-,} \mathrm{g+} \mathrm{g-} \mathrm{g-}$ $\mathrm{g}+\mathrm{G}-\mathrm{g}+$ (within $1 \mathrm{kcal} / \mathrm{mol}$ energy range). Thus, the most stable, $\mathrm{T} g+$ hydroxymethylene, orientation of the $\beta$-D-galactose monomer does not occur in $\mathrm{Le}^{\mathrm{x}}$ or in its analogues. The second and third most stable rotamers do occur, however, in somewhat distorted forms due to the interresidue interactions.

Torsion Angles in the Fucose Moiety. The L-fucose residue has similar conformations in the most stable MM2* and $\mathrm{HF}$ rotamers of Le $\mathrm{x}^{\mathrm{x}}$ analogues: $\mathrm{tg}-\mathrm{t} \mathrm{t}$ (cf. Tables 4 and 5). This clockwise direction of the $\mathrm{OH}$ groups corresponds to the pattern found in the most stable ${ }^{1} \mathrm{C}_{4}$ L-fucose molecule. ${ }^{10,13}$ The interresidue interactions influence the rotamers of fucose residue. This will be discussed in the next section.

3.1.5. Interresidue Interactions. In our previous study on $\mathrm{Le}^{\mathrm{x}}, \mathrm{O}_{\mathrm{Gal}} \mathrm{H} \rightarrow \mathrm{O}[1,3]_{\text {link }}$ and $\mathrm{O} 2_{\mathrm{Fuc}} \mathrm{H} \rightarrow \mathrm{O}=\mathrm{C}_{\mathrm{GlcNAc}}$ interactions were observed in the most stable MM2* rotamers. The clockwise (fucose) and the counterclockwise (galactose) chain of hydrogen bonds are not connected any other way in those MM2* rotamers. In the most stable $\mathrm{HF} / 6-31 \mathrm{G}(\mathrm{d})$ rotamer, both chains of the hydrogen bonds point in the clockwise direction and the two residues are connected by an $\mathrm{O6}_{\mathrm{Gal}} \mathrm{H} \rightarrow \mathrm{O} 3_{\mathrm{Fuc}}$ interaction. The longest continuous chain of eight $\mathrm{OH}$ interactions occurs in rotamer 9 of $\mathbf{I I}\left(\mathrm{O}_{\mathrm{GlcNAc}} \mathrm{H} \rightarrow \mathrm{O} 2_{\mathrm{Gal}}, \mathrm{O}_{\mathrm{Gal}} \mathrm{H} \rightarrow\right.$ $\mathrm{O} 3_{\text {Fuc }}$, and $\mathrm{O} 2_{\mathrm{Fuc}} \mathrm{H} \rightarrow \mathrm{O}=\mathrm{C}_{\mathrm{GlcNAc}}$ donor $\rightarrow$ acceptor interresidue interactions occur in this rotamer). ${ }^{27}$

In $\mathrm{Le}^{\mathrm{x}}$ analogues III and $\mathbf{I V}$, the interactions are different than in II or I due to the missing pieces of the GlcNAc residue. The MM2* and HF structures agree well for the first three rotamers of III (cf. Tables 2 and 4). The following interactions occur: in rotamer $1, \mathrm{O} 2_{\mathrm{Fuc}} \mathrm{H} \rightarrow \mathrm{O} 6_{\mathrm{Gal}}, \mathrm{O} 5_{\mathrm{Gal}}$; in rotamer 2, $\mathrm{O} 6_{\mathrm{Gal}} \mathrm{H} \rightarrow \mathrm{O} 2_{\text {Fuc }}, \mathrm{O}[1,1]_{\text {link }}$, and $\mathrm{O} 3_{\mathrm{Fuc}} \mathrm{H} \rightarrow \mathrm{O} 4_{\mathrm{Gal}}$; in rotamer 3 , $\mathrm{O} 2_{\mathrm{Fuc}} \mathrm{H} \rightarrow \mathrm{O}_{\mathrm{Gal}}$.

MM2* rotamer 4 of III has no interresidue interaction. However, during the HF/6-31G(d) geometry optimization this rotamer was transformed to the most stable rotamer 1 of III (cf. Table 4).

In $\mathrm{MM} 2 *$ rotamer 5, the interresidue interaction is similar to that of in rotamer $1\left(\mathrm{O} 2_{\mathrm{Fuc}} \mathrm{H} \rightarrow \mathrm{O}_{\mathrm{Gal}}, \mathrm{O}_{\mathrm{Gal}}\right)$. However, the fucose position is different $\left(\tau 1_{\mathrm{Fuc}} \approx-70^{\circ}\right)$. The MM2* and the HF structures agree qualitatively for this rotamer (cf. Tables 2 and 4).

The MM2* and HF results are qualitatively different for rotamer 6 . The $\mathrm{O} 2_{\mathrm{Fuc}} \mathrm{H} \rightarrow \mathrm{O}_{\mathrm{Gal}}, \mathrm{O} 5_{\mathrm{Gal}}$, interresidue interaction in the MM2* equilibrium structure changes to $\mathrm{O}_{\mathrm{Gal}} \mathrm{H} \rightarrow \mathrm{O} 2_{\mathrm{Fuc}}$ in the equilibrium HF structure. Meanwhile, the value of $\tau 1_{\text {Fuc }}$ changes from $177^{\circ}$ to $-126^{\circ}$ (cf. Tables 2 and 4 ).

MM2* rotamer 7 agrees well with the most stable rotamer 1 of II, and the $\mathrm{O}_{\mathrm{Gal}} \mathrm{H} \rightarrow \mathrm{O}[1,1]_{\text {link }}$ occurs in this rotamer. The MM2* and the HF structures agree qualitatively for this rotamer (cf. Tables 2 and 4). The remaining rotamers in Table 2 show no new type of interresidue interaction. The MM2* rotamer 9 is not stable according to the HF method and it was transformed to rotamer 7 (cf. Table 4).

The MM2* and HF structures agree qualitatively for the rotamers of IV except for the rotamers 7 and 8 (cf. Tables 3 and 5). These latter rotamers are not stable and they were changed considerably during the HF geometry optimization. Typical intermoiety interactions are the following: $\mathrm{O} 2_{\mathrm{Fuc}} \mathrm{H} \rightarrow$ $\mathrm{O}_{\mathrm{Gal}}, \mathrm{O}_{\mathrm{Gal}} ; \mathrm{O}_{\mathrm{Gal}} \mathrm{H} \rightarrow \mathrm{O} 2_{\mathrm{Fuc}}, \mathrm{O}[1,1]_{\text {link }}$; and $\mathrm{O} 3_{\mathrm{Fuc}} \mathrm{H} \rightarrow \mathrm{O}_{\mathrm{Gal}}$. The essential difference between the rotamers of III and IV is that in IV the $\mathrm{O} 2_{\mathrm{Fuc}} \mathrm{H} \rightarrow \mathrm{O}_{\mathrm{Gal}}, \mathrm{O} 5_{\mathrm{Gal}}$ interresidue interactions occur three times with a rather different fucose position $\left(\tau 1_{\text {Fuc }} \approx-70^{\circ}-80^{\circ}\right.$ instead of $\left.180^{\circ}\right) .{ }^{28}$ Such rotamers do not occur among the most stable rotamers of $\mathbf{I}$ and $\mathbf{I I}{ }^{27}$

3.2. Relative Stability of the Rotamers. Figure 9 summarizes the relative energies of the rotamers of II, III, and IV. Figure 9 reveals that the MM2* relative energy differences are small (less than $1 \mathrm{kcal} / \mathrm{mol}$ ) for the first 11 most stable rotamers of II. The HF/6-31G(d) method yields more than $4.5 \mathrm{kcal} / \mathrm{mol}$ energy difference for the same rotamers of II. In this respect, the MM2* and HF/6-31G(d) relative energies of the first four conformers of $\beta$-D-galactose differ by $3 \mathrm{kcal} / \mathrm{mol}$. The origin of this large energy difference is not different optimized geometries, because the equilibrium MM2* and HF geometries agree qualitatively. This geometric agreement supports the use of MM2*-SUMM conformational space as a starting point for further HF/6-31G(d) or higher level studies. The HF/6-31G(d) energetic order for II is $4,1,9,2,10,6,3,5,7,8,11$, which differs considerably from the energetic order obtained by the MM2* method. Thus, investigation of large number of MM2* rotamers is necessary in order to find the global minimum.

Previously, we showed that the MM2* relative energies do not reflect consistently the structural changes between the rotamers (i.e., no correlation was found between the MM2* relative energies of conformers of I and II $\left.\left(R^{2}=0.274\right)\right) .{ }^{7}$ In contrast, the HF/6-31G(d) method reflects consistently the structural changes between the rotamers. Comparison of the seven rotamers of I and II obtained from the HF/6-31G(d) method shows the same energetic order for rotamers of $\mathbf{I}$ and II and a good correlation for the energy differences $\left(R^{2}=\right.$ 0.994). ${ }^{7}$

Comparison of the HF relative energies of rotamers of II shows that replacing the $\mathrm{O}_{\mathrm{GlcNAc}} \mathrm{H} \rightarrow \mathrm{O}_{\mathrm{GlcNAc}}$ intraresidue interaction by an $\mathrm{O}_{\mathrm{GlcNAc}} \mathrm{H} \rightarrow \mathrm{O} 2_{\mathrm{Gal}}$ interresidue interaction destabilizes the molecule by $1.8 \mathrm{kcal} / \mathrm{mol}$ (cf. rotamers 4 and 9 of II in Figure 9). This result shows that the interresidue hydrogen-bonding interactions are not required for the stability of the stacked conformation (observed in the X-ray ${ }^{9}$ and NOE $\mathrm{NMR}^{5}$ experiments) in the gas phase.

Tables 2 and 3 show the energies, relative energies, and the torsion angles that identify the various rotamers obtained from the MM2*-SUMM conformational search for compounds III 

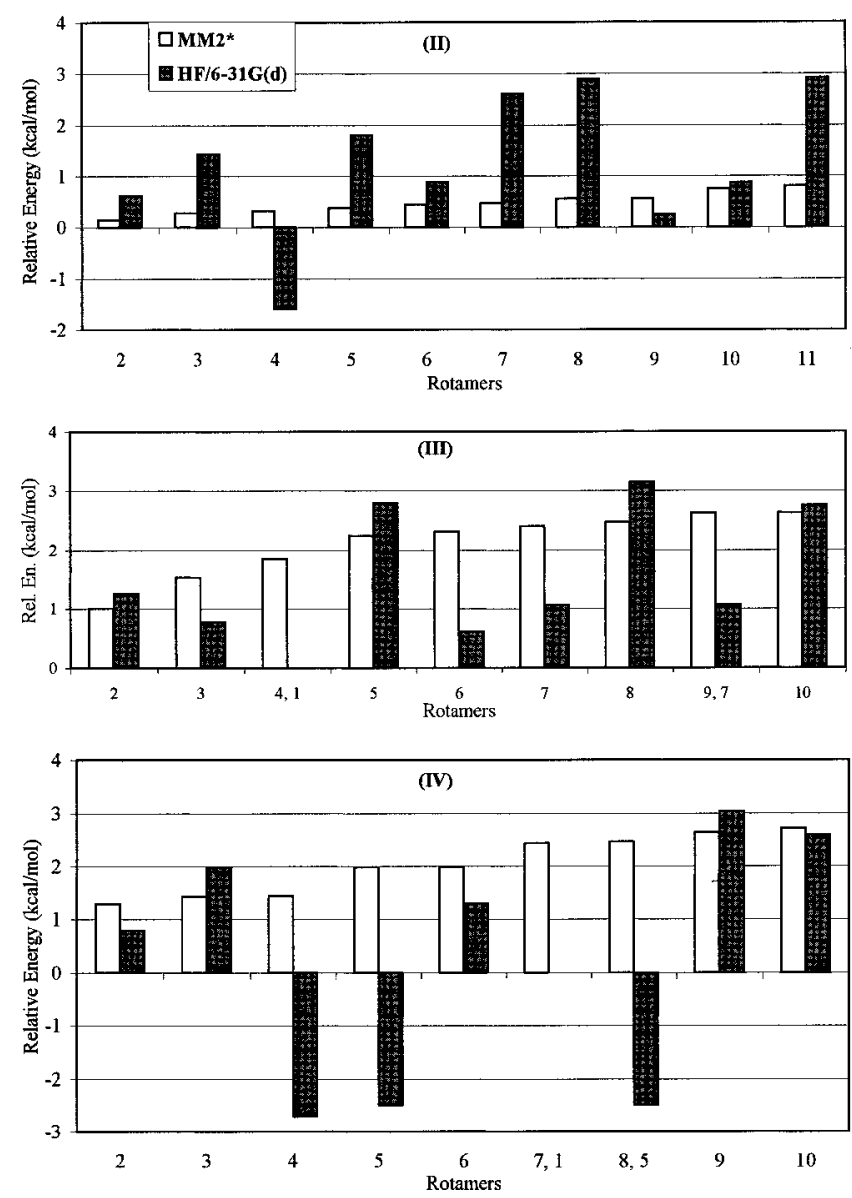

Figure 9. Relative energies of the lowest energy rotamers in the conformational space of $\mathbf{I I},{ }^{7}$ III, and IV calculated with MM2* and HF/6-31G(d) methods. The rotamers are numbered according to the MM2* energetic order (the energy of the first rotamer is used as reference $-0 \mathrm{kcal} / \mathrm{mol}$ ). Two numbers separated by comma signal that the given MM2* rotamer (first number) is not stable according to the $\mathrm{HF} / 6-31 \mathrm{G}(\mathrm{d})$ method, and it was transformed to a different rotamer (second number) during the geometry optimization.

and IV, respectively. Tables 4 and 5 show the corresponding $\mathrm{HF} / 6-31 \mathrm{G}(\mathrm{d})$ energies and relative energies. Comparison of the MM2* relative energies for II, III, and IV provides a considerably larger (nearly $3 \mathrm{kcal} / \mathrm{mol}$, cf. Figure 9) range of energy for the 10 lowest energy rotamers of III and IV than for the 11 lowest energy rotamers of II (less than $1 \mathrm{kcal} / \mathrm{mol}$ ). Comparison of the rotamers of II and III shows that rotamer 1 of III corresponds to rotamers 6 and 11 of II, rotamer 4 of III corresponds to rotamers 2 and 7 of II, and rotamer 7 of III corresponds to rotamers 1 and 5 of II . $^{27,28}$ The other low-energy rotamers of III do not occur in the conformational space of II and vice versa. The above-mentioned rotamer pairs of II have identical fucose and galactose rotamers. The difference is in the hydroxymethylene rotamer of GlcNAc residue. According to the $\mathrm{HF}$ results the $\mathrm{G}-\mathrm{g}+$ rotamer is about $2.0 \mathrm{kcal} / \mathrm{mol}$ more stable than the corresponding $\mathrm{G}+\mathrm{g}-$ rotamer.

As noted before, equilibrium MM2* and HF geometries of II agree qualitatively. However, this is not generally true for the equilibrium MM2* and HF geometries of III and IV. Thus, the large relative energy differences between the MM2* and HF method are caused by the qualitatively different molecular geometries in several cases. The rotamers 4 and 9 of III and the rotamers 7 and 8 of $\mathbf{I V}$ are not stable according to the HF/ 6-31G(d) method (cf. Figure 9). The essential differences between these rotamers are in the positions of the fucose part of the molecule (cf. $\tau 1_{\text {Fuc }}$ in Tables $2-5$ for the corresponding rotamers). A similar large difference between the equilibrium values of $\tau 1_{\text {Fuc }}$ can be found in rotamer 6 of III (cf. Tables 2 and 3). This suggests a larger mobility for the fucose residue in agreement with the experimental results. Our results show that the most stable rotamer of III (regardless of method) has a stacked conformation, similar to I, and II. Rotamer 7 of III deserves special attention. This rotamer is very similar to the (stacked) rotamer 1 of II. This rotamer is not particularly stable according to MM2*, but it is according to the HF/6-31G(d) method (cf. Table 4 and Figure 9). Rotamer 7 is so stable that rotamer 9 of III was transformed to it during the HF geometry optimization. This close similarity of the most stable structures of I, II, and III might explain the similar biological activities of I and III.

This is not applicable to IV because according to the HF/6$31 \mathrm{G}(\mathrm{d})$ method the nonstacked rotamers 4 and 5 are the most stable. These rotamers are more than $2.5 \mathrm{kcal} / \mathrm{mol}$ more stable than the stacked rotamers (cf. Figure 9) that resemble the most stable rotamers of $\mathbf{I}$ and $\mathbf{I I}$.

Our ab initio structures and energies might provide a good test set for any MM force field claimed to yield good results for sugars. Although the HF/6-31G(d) method usually provides excellent relative energies for the monosaccharides, it remains to be proven that it is also good for oligosaccharides. However, it is too expensive to obtain good quality, optimized molecular geometries with correlation effects for molecules of this size.

\section{Conclusions}

The following conclusions can be drawn from our analysis:

1. The experimental and calculated glycosidic torsion angles correspond to a so-called "stacked" conformation for free $\mathrm{Le}^{\mathrm{x}}$. In this arrangement, the plane of the fucose ring is nearly parallel with the plane of the galactose ring. The key torsion angles for Fuc- $\alpha-1,3-$ GlcNAc and Gal- $\beta-1,4-G l c N A c$ glycosidic bonds ( $\tau 1_{\text {Fuc }}, \tau 3_{\text {GlcNAc }}, \tau 4_{\text {GlcNAc }}$, and $\tau 1_{\text {Gal }}$ ) mostly keep their value in the different environments (solid, liquid, and gas phases). The $\mathrm{ab}$ initio torsion angles agree considerably better with the experimental results. Another essential difference between the MM2* and ab initio results is that the latter provide better differentiation of the rotamers.

2. In the strongly bound $s \mathrm{Se}^{\mathrm{x}}-\mathrm{E}$-selectin complex, both glycosidic linkage (four glycosidic torsions) were considerably distorted relative to the ab initio results. In the less strongly bound $\mathrm{sLe}^{\mathrm{x}}-\mathrm{L}$-selectin complex, only the Gal- $\beta-1,4-\mathrm{GlcNAc}$ linkage (both glycosidic torsions) was distorted. In the weakly bound $\mathrm{sLe}^{\mathrm{x}} \mathrm{P}$-selectin complex, only a single glycosidic torsion angle $\left(\tau 1_{\text {Fuc }}\right)$ was slightly distorted.

3 . The linkages connecting the cyclohexanediol and the 1,2ethanediol to fucose and galactose are characterized by $\tau 1_{\text {Fuc }}$, $\tau 1_{\text {diol }}, \tau 2_{\text {diol }}$, and $\tau 1_{\text {Gal }}$ torsions. In III and especially in $\mathbf{I V}$, the preferred exoanomeric position $\left(\tau 1_{\text {Fuc }} \approx 180^{\circ}\right)$ is much more populated by the low-energy rotamers, and only a few, one or two rotamers take the $\tau 1_{\text {Fuc }} \approx 165^{\circ}$ position populated in $\mathrm{Le}^{\mathrm{x}}$.

4. An approximate linear dependence of $\tau 1_{\text {Fuc }}$ vs $\tau 3_{\text {GlcNAc }}$ or $\tau 1_{\text {diol }}$ was observed in the ab initio structures for II and III. According to the ab initio results the glycosidic linkage conformation found in the $\mathrm{sLe} \mathrm{e}^{\mathrm{x}}-\mathrm{E}$-selectin complex, characterized by $\tau 1_{\mathrm{Fuc}} \approx 190^{\circ}$ and $\tau 3_{\mathrm{GlcNAc}} \approx 133^{\circ}$ is not stable in the unbound $\mathrm{sLe}^{\mathrm{x}}$. The ab initio calculations would suggest $\tau 1_{\mathrm{Fuc}}$ $\approx 190^{\circ}$ and $\tau 3_{\mathrm{GlcNAc}} \approx 168^{\circ}$ or $\tau 1_{\mathrm{Fuc}} \approx 160^{\circ}$ and $\tau 3_{\mathrm{GlcNAc}} \approx$ $133^{\circ}$ torsion angle pairs.

5 . Nonstacked rotamers occur only once among the rotamers of III, and that rotamer is not particularly stable $(\Delta E=2.3$ $\mathrm{kcal} / \mathrm{mol})$. However such rotamers are more frequent among the rotamers of $\mathbf{I V}$ (e.g., rotamers 2,4 , and $5, \tau 1_{\mathrm{Fuc}} \approx-70^{\circ}-$ 
$80^{\circ}$ ). This clearly shows that while the conformational space of III is rather similar to that of I and II, the conformational space of IV is more different.

6. The most stable rotamer of the galactose is coded as $\mathrm{t} \mathrm{t} \mathrm{t} \mathrm{t} \mathrm{G-g-} \mathrm{in} \mathrm{III} \mathrm{and} \mathrm{IV} \mathrm{(rotamer} \mathrm{1).} \mathrm{The} \mathrm{hydroxyls} \mathrm{of} \mathrm{the}$ hydrogen-bonded chain of galactose point in the counterclockwise direction. 19 out 20 most stable rotamers of III and IV show this counterclockwise pattern. The only exception is the rotamer 4 of IV. In this rotamer, the hydroxyl groups of galactose point in a clockwise direction and are coded as $\mathrm{tg}-$ $\mathrm{g}-\mathrm{g}+\mathrm{G}-\mathrm{g}+$. In the most stable MM2* rotamers of $\mathrm{Le}^{\mathrm{x}}$ analogues, the torsion angles of the fucose residue have the following orientation: $\mathrm{tg}-\mathrm{t} \mathrm{t}$. This clockwise direction of the hydroxyls corresponds to the pattern found in the most stable ${ }^{1} \mathrm{C}_{4} \mathrm{~L}$-fucose monomer. In the most stable MM2* Le ${ }^{\mathrm{x}}$ structures, the hydrogen-bonded chains of galactose (with counterclockwise direction, $\mathrm{t} \mathrm{t} \mathrm{t} \mathrm{t} \mathrm{G+g-} \mathrm{rotamer)} \mathrm{and} \mathrm{fucose} \mathrm{(with} \mathrm{clockwise}$ direction, $\mathrm{t} g-\mathrm{t} t$ rotamer) residues are not connected directly.

7. Qualitative agreement can be observed between the MM2* and $\mathrm{HF} / 6-31 \mathrm{G}(\mathrm{d})$ equilibrium geometries of the first 11 rotamers of $\mathrm{Le}^{\mathrm{x}}$ II, despite large relative energy differences (i.e., different energetic order). However, qualitative differences can be observed between the HF and MM2* results for several rotamers of III and IV. Some of the rotamers found by the MM2*SUMM conformational searches are not stable according to the HF/6-31G(d) results. It can be observed that HF conformational space of III is more similar to that of I and II than it is to the conformational space of IV. The essential difference between the rotamers of III and IV is that in IV the $\mathrm{O} 2_{\mathrm{Fuc}} \mathrm{H} \rightarrow \mathrm{O} 6_{\mathrm{Gal}}$, $\mathrm{O} 5_{\mathrm{Gal}}$ interresidue interactions occur three times with a rather different fucose position $\left(\tau 1_{\text {Fuc }} \approx-70^{\circ}-80^{\circ}\right.$ instead of $\left.180^{\circ}\right)$. Such rotamers do not occur among the most stable rotamers of I and II.

8. The MM2* relative energies differ only slightly (less than $1 \mathrm{kcal} / \mathrm{mol}$ ) for the rotamers of II. This is in sharp contradiction to the HF/6-31G(d) relative energies of II. The HF/6-31G(d) method yields more than $4.5 \mathrm{kcal} / \mathrm{mol}$ energy difference for the first 11 most stable rotamers of II. According to our experience, the HF/6-31G(d) method reflects consistently the structural changes between the rotamers.

9. The close resemblance of the most stable structures of $\mathbf{I}$, II, and III might provide an explanation for the similar biological activity of I and III. This reasoning is not applicable to IV. According to the HF/6-31G(d) method, the nonstacked rotamers of IV are more stable (by more than $2.5 \mathrm{kcal} / \mathrm{mol}$ ) than the stacked rotamers that resemble the rotamers of $\mathbf{I}$ and II.

Acknowledgment. We thank Dr. A. D. French for his comments and valuable suggestions on the manuscript. We also thank G. Schubert for assistance. We also extend our gratitude to the Corporate Computing Network Department at Cray Research/Silicon Graphics Inc. for providing computer time to carry out most of these calculations.

\section{References and Notes}

(1) (a) Ball, G. E.; O’Neill, R. A.; Schultz, J. E.; Lowe, J. B.; Weston, B. W.; Nagy, J. O.; Brown, E. G.; Hobbs, C. J.; Bednarski, M. D. J. Am. Chem. Soc. 1992, 114, 5449. (b) Lin, Y.-C.; Hummel, C. W.; Huang, D.H.; Ichikawa, Y.; Nikolau, K. C.; Wong, C.-H. J. Am. Chem. Soc. 1992, 114,5452

(2) Ichikawa, Y.; Lin, Y.-C.; Dumas, D. P.; Shen, G.-J.; Garcia-Junceda, E.; Williams, M. A.; Bayer, R.; Ketcham, C.; Walker, L. E.; Paulson, J. C.; Wong, C.-H. J. Am. Chem. Soc. 1992, 114, 9283.

(3) (a) Tyrell, D.; James, P.; Rao, B. N. N.; Foxall, C.; Abbas, S.; Dasgupta, F.; Nashed, M.; Hasegawa, A.; Kiso, M.; Asa, D.; Kidd, J.;
Bradley, B. K. Proc. Natl. Acad. Sci. U.S.A. 1991, 88, 10732. (b) Bradley, B. K.; Kiso, M.; Abbas, S.; Nikrad, P.; Srivastava, O.; Foxall, C.; Oda, Y.; Hasegawa, A. Glycobiology 1993, 3, 633. (c) DeFrees, S. A.; Gaeta, F. C. A.; Lin, Y.-C.; Ichikawa, Y.; Wong, C.-H. J. Am. Chem. Soc. 1993, 115, 7549. (d) Rampal, J. Y.; Zheng, Z.-L.; Perez, C.; Walker, L. E.; DeFrees, S. A.; Gaeta, F. C. A. J. Med. Chem. 1994, 37, 3459 1994. (e) Giannis, A. Angew. Chem., Int. Ed. Engl. 1994, 33, 178.

(4) Simanek, E. E.; McGarvey, G. J.; Jablonowski, J. A.; Wong, C.H. Chem. Rev. 1998, 98, 833.

(5) Poppe, L.; Brown, G. S.; Philo, J. S.; Nikrad, P. V.; Shah, B. H. J. Am. Chem. Soc. 1997, 119, 1727-1736.

(6) Bamford, M. J.; Bird, M.; Gore, P. M.; Holmes, D. S.; Priest, R.; Prodger, J. C.; Saez, V. Bioorg. Med. Chem. Lett. 1996, 6, 239.

(7) Csonka, G. I.; Sosa, C. P.; Csizmadia, I. G. J. Phys. Chem. A 2000, 104, 3381

(8) Miller, K. E.; Mukhopadhyay, C.; Cagas, P.; Bush, C. A. Biochemistry 1992, 31, 6703.

(9) Perez, S.; Mouhous-Riou, N.; Nifant'ev, N. E.; Tsvetkov, Y. E.; Bachet, B.; Imberty, A., Glycobiology 1996, 6, 537.

(10) Csonka, G. I.; Éliás, K.; Csizmadia, I. G. Chem. Phys. Lett. 1996, 257, 49.

(11) Csonka, G. I.; Éliás, K.; Kolossváry, I.; Sosa, C. P.; Csizmadia, I. G. J. Phys. Chem. A 1998, 102, 1219.

(12) Csonka, G. I.; Kolossváry, I.; Császár, P.; Éliás, K.; Csizmadia, I. G. J. Mol. Struct. (THEOCHEM) 1997, 395-396, 29.

(13) Csonka, G. I.; Éliás, K.; Csizmadia, I. G. J. Comput. Chem. 1997, 18,330 .

(14) Barrows, S. E.; Strorer, J. W.; Cramer, C. J.; French, A. D.; Truhlar, D. G. J. Comput. Chem. 1998, 19, 1111.

(15) Damm, W.; Frontera, A.; Tirado-Rives, J.; Jorgensen, W. L. J. Comput. Chem. 1997, 18, 1955.

(16) Reilig, S.; Schlenkrich, M.; Brinkmanmn, J. J. Comput. Chem. 1996, 17,450 .

(17) Senderowitz, H.; Parish, C.; Still, W. C. J. Am. Chem. Soc. 1996 118, 2078.

(18) Kneisler, J. R.; Allinger, N. L. J. Comput. Chem. 1996, 17, 757.

(19) Goodman, J. M.; Still, W. C. J. Comput. Chem. 1991, 12, 1110.

(20) Still, W. C. MacroModel 5.0, Columbia University, http://www.columbia.edu/cu/chemistry/mmod/mmod.html.

(21) (a) Allinger, N. L. J. Am. Chem. Soc. 1977, 99, 8127. (b) Different versions are available from Quantum Chemistry Program Exchange, University of Indiana, Bloomington, IN 47405; http://ccl.osc.edu/ccl/qcpe/ QCPE/catalog.html.

(22) Gundertofte, K.; Liljefors, T.; Norrby, P.-O.; Pettersson, I. J. Comput. Chem. 1996, 17, 429.

(23) (a) Schlegel, H. B. J. Comput. Chem. 1982, 3, 214. (b) Peng, C.; Ayala, P. Y.; Schlegel, H. B.; Frisch, M. J. J. Comput. Chem. 1996, 17, 49 .

(24) Gaussian 98; Frisch, M. J.; Trucks, G. W.; Schlegel, H. B.; Scuseria, G. E.; Robb, M. A.; Cheeseman, J. R.; Zakrzewski, V. G.; Montgomery, J. A.; Stratmann, R. E.; Burant, J. C.; Dapprich, S.; Millam, J. M.; Daniels, A. D.; Kudin, K. N.; Strain, M. C.; Farkas, O.; Tomasi, J.; Barone, V.; Cossi, M.; Cammi, R.; Mennucci, B.; Pomelli, C.; Adamo, C.; Clifford, S.; Ochterski, J.; Petersson, G. A.; Ayala, P. Y.; Cui, Q.; Morokuma, K.; Malick, D. K.; Rabuck, A. D.; Raghavachari, K.; Foresman, J. B.; Cioslowski, J.; Ortiz, J. V.; Stefanov, B. B.; Liu, G.; Liashenko, A.; Piskorz, P.; Komaromi, I.; Gomperts, R.; Martin, R. L.; Fox, D. J.; Keith, T.; Al-Laham, M. A.; Peng, C. Y.; Nanayakkara, A.; Gonzalez, C.; Challacombe, M.; Gill, P. M. W.; Johnson, B. G.; Chen, W.; Wong, M. W.; Andres, J. L.; Head-Gordon, M.; Replogle, E. S.; Pople, J. A. Gaussian, Inc.: Pittsburgh, PA, 1998.

(25) Ng, K. K.-S.; Weis, W. I. Biochemistry 1997, 36, 979.

(26) Imberty, A. Curr. Opin. Struct. Biol. 1997, 7, 617, and references therein.

(27) http://web.inc.bme.hu/mols/lex/lexme.htm, and http://web.inc. bme.hu/mols/lex/lexh.htm.

(28) http://web.inc.bme.hu/mols/lex/chex.htm, and http://web.inc.bme.hu/ mols/lex/diol.htm.

(29) (a) French, A. D.; Rowland, R. S.; Allinger, N. L. In Computer Modeling of Carbohydrate Molecules; ACS Symposium Series No. 430; French, A. D., Brady, J. W., Eds.; American Chemical Society: Washington, DC, 1990; p 120. (b) Tran, V.; Brady, J. W. In Computer Modeling of Carbohydrate Molecules; ACS Symposium Series No. 430; French, A. D., Brady, J. W., Eds.; American Chemical Society: Washington, DC, 1990; p 213.

(30) Cramer, C. J.; Truhlar, D. E. J. Am. Chem. Soc. 1993, 115, 5745.

(31) Polavarapu, P. L.; Ewig, C. S. J. Comput. Chem. 1992, 13, 1255.

(32) Woods, R. Carbohydrate force fields; Ecyclopedia of Computational Chemistry; Schleyer, P. V. R., Allinger, N. L., Clark, T., Gasteiger, J., Kollman, P. A., Schaefer III, H. F., Schreiner, P. R., Eds.; John Wiley \& Sons: Chichester, UK, 1998; Vol. 1, pp 220-233.

(33) French, A. D.; Kelterer, A.-M.; Johnson, G. P.; Dowd, M. K.; Cramer, C. J. J. Comput. Chem., accepted.

(34) http://web.inc.bme.hu/mols/gal/hf6geom.htm. 